\title{
Application of functional vincristine plus dasatinib liposomes to deletion of vasculogenic mimicry channels in triple-negative breast cancer
}

\author{
Fan Zeng ${ }^{1}$, Rui-Jun Ju${ }^{1}$, Lei Liu ${ }^{1}$, Hong-Jun Xie ${ }^{1}$, Li-Min Mu ${ }^{1}$, Yao Zhao ${ }^{1}$, Yan Yan ${ }^{1}$,

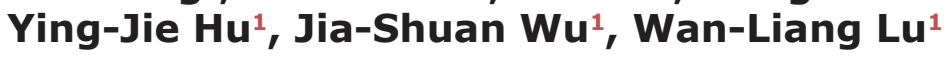 \\ ${ }^{1}$ Beijing Key Laboratory of Molecular Pharmaceutics and New Drug System, State Key Laboratory of Natural and Biomimetic \\ Drugs, School of Pharmaceutical Sciences, Peking University, Beijing 100191, China \\ Correspondence to: \\ Wan-Liang Lu, e-mail: luwl@bjmu.edu.cn \\ Keywords: functional liposome, vincristine, dasatinib, vasculogenic mimicry channel, triple-negative breast cancer \\ Received: July 12, $2015 \quad$ Accepted: September 16, $2015 \quad$ Published: September 28, 2015
}

\section{ABSTRACT}

Standard chemotherapy cannot eradicate triple-negative breast cancer (TNBC) while the residual cirici lial!s b'eacily sorm the vasculogenic mimicry (VM) channels, which lead to the relapse of cancer after treatment. In this study, the functional vincristine plus dasatinib liposomes, modified by a targeting molecule DSPE-PEG ${ }_{2000}-c($ RGDYK), were fabricated to address this issue. The investigations were performed on TNBC MDA-MB-231 cells and MDA-MB-231 xenografts in nude mice. The liposomes exhibited the superior performances in the following aspects: the enhancement of cellular uptake via targeted action; the induction of apoptosis via activation of caspase 8, 9, and 3, increased expression of Bax, decreased expression of $\mathrm{MCl}-1$, and generation of reactive oxygen species (ROS); and the deletion of VM channels via inhibitions on the VM channel indicators, which consisted of vascular endothelial-cadherin (VE-Cad), focal adhesion kinase (FAK), phosphatidylinositide 3-kinase (PI3K), and matrix metallopeptidases (MMP-2, and MMP-9). Furthermore, the liposomes displayed the prolonged circulation time in the blood, the increased accumulation in tumor tissue, and the improved therapeutic efficacy along with deletion of VM channels in the TNBC-bearing mice. In conclusion, the nanostructured functional drug-loaded liposomes may provide a promising strategy for the treatment of invasive TNBC along with deletion of VM channels.

\section{INTRODUCTION}

Breast cancer is the most common malignant disease and a major cause of mortality among women worldwide [1]. Nearly 1.4 million individuals are diagnosed with breast cancer globally, with more than 450,000 deaths per year [2]. Among these cases, approximately $15-20 \%$ are characterized as the triple-negative breast cancer (TNBC) phenotype, namely, the absence of estrogen receptors, progesterone receptors and human epidermal growth factor receptor $2[3,4]$. Patients with TNBC have a very poor prognosis because TNBC is highly invasive and associated with a high rate of cancer metastasis and recurrence $[5,6]$.

In recent years, increasing evidences have indicated that highly patterned vasculogenic mimicry (VM) channels are formed by TNBC cells instead of endothelial cells as an alternative microcirculation pathway, and these channel-forming TNBC cells are highly drug resistant [7, 8]. Comprehensive treatments, which consist of surgery, radiation and standard chemotherapy, cannot completely eliminate TNBC cells $[9,10]$. In hypoxic conditions, the residual cancer cells readily proliferate via the formation of highly patterned VM channels, which provide nutrients to the relapsed cancer cells. Consequently, the elimination of VM channels plays a crucial role in a successful treatment of TNBC.

In this study, we hypothesized that functional vincristine plus dasatinib liposomes could eliminate TNBC cells along with destroying VM channels. In these nanostructured liposomes, a cyclic peptide $\mathrm{c}\left(\mathrm{RGD}_{\mathrm{y}} \mathrm{K}\right)$ was 
conjugated with N-hydroxysuccinimidyl-polyethylene glycol distearoylphosphatidyl ethanolamine (DSPE$\mathrm{PEG}_{2000}$-NHS) and used as a targeting molecule to modify the liposome surface. Vincristine was used as an anticancer drug, and dasatinib was employed as VM channel inhibitor.

Vincristine is a cell cycle-specific anticancer agent. The cytotoxic activity of vincristine is related to its activities regarding the inhibition of microtubules and the alteration of tubulin polymerization equilibrium, which thus causes the arrest of cell division in metaphase [11]. Dasatinib is an inhibitor of sarcoma gene family kinases (SFKs) [12]. Studies indicate that SFKs play a central role in multiple signaling pathways that regulate cell adhesion, invasion and motility, and are also involved in interactions with numerous breast cancer associated growth factors $[13,14]$. Thus, as an inhibitor of SFKs, dasatinib exhibits multiple effects on cancer, including anti-proliferative activity, induction of apoptosis, and inhibition of invasion [15-17]. Because of these properties, dasatinib represents a promising inhibitor in TNBC treatment.

Conventional chemotherapy has demonstrated unfavorable pharmacokinetic properties and systemic toxicities as a result of the direct delivery of free drugs into the circulatory system [18]. Pegylated liposomes with suitable particle sizes have been demonstrated to improve the therapeutic index of drugs by prolonged circulation in the blood and enhanced tumor accumulation in cancer tissue due to the enhanced permeability and retention (EPR) effects [19, 20]. Besides, the liposomes are biocompatible and can entrap both hydrophilic and hydrophobic pharmaceutical agents, protecting them from external damage and allowing to local concentrated drug delivery. Therefore, development of a tool to allow for constant and selective delivery of therapeutics is desirable. Active targeting was achieved by conjugating $\mathrm{c}\left(\mathrm{RGD}_{\mathrm{y}} \mathrm{K}\right)$ with DSPE-PEG ${ }_{2000}-\mathrm{NHS}$ and modifying the liposome surface in this study. $\mathrm{C}\left(\mathrm{RGD}_{\mathrm{y}} \mathrm{K}\right)$ is a cyclic peptide that has a specific affinity for the integrin receptor, which is overexpressed on many malignant cancer cells $[21,22]$. This cyclic peptide offers a potential avenue for nanostructured drug carriers to access target cancer cells.

The objectives of this study were to fabricate functional vincristine plus dasatinib liposomes to eliminate VM channels in the treatment of invasive TNBC and to define the action mechanism (Figure 1).

\section{RESULTS}

\section{Fabrication of functional vincristine plus dasatinib liposomes}

The characterization of targeting molecule and liposomes were shown in Figure 2. The results from the matrix-assisted laser desorption/ionization time of flight mass spectrometer (MALDI-TOF-MS) spectra of DSPE-PEG $_{2000}-\mathrm{NHS}$ (Figure 2A1) and DSPE-PEG ${ }_{2000}{ }^{-}$ $\mathrm{c}(\mathrm{RGDyK})$ (Figure 2A2) indicated that the $\mathrm{c}(\mathrm{RGDyK})$ peptide was successfully conjugated to the distal end of DSPE-PEG ${ }_{2000}$-NHS via a nucleophilic substitution reaction. Observation under an atomic force microscope (AFM) indicated that the liposome was round in shape with a smooth surface and approximately $100 \mathrm{~nm}$ in diameter (Figure 2B1 and 2B2). The in vitro release rates of vincristine and dasatinib from the liposomes were $<3 \%$ within the initial $2 \mathrm{~h}$ and were $<20 \%$ over $24 \mathrm{~h}$ (Figure 2C).

Table 1 lists the characterization of functional drugs-loaded liposomes. The results indicated that the average particle sizes of the liposomes were in the range of 100-107 nm with a narrow polydispersity index (PDI; $\leq 0.2)$, and the charge values were slightly negative $(-6 \mathrm{mV})$. The encapsulation efficiencies of vincristine and dasatinib were both $>90 \%$ in all prepared liposomes.

\section{Cellular uptake by TNBC cells and targeting effect}

To evaluate the cellular uptake by TNBC cells and targeting effect, the fluorescence probe coumarin was used to label the liposomes. Figure $3 \mathrm{~A}$ and $3 \mathrm{~B}$ indicate the cellular uptake by MDA-MB-231 cells after treatments with varying formulations. Results showed that the rank of cellular uptake was free coumarin $>$ functional coumarin liposomes $>$ coumarin liposomes $>$ blank control.

Figure 3C displays the targeting effect of varying coumarin labeled liposomes. In the confocal images, integrin $\beta 3$ receptor exhibited red fluorescence, whereas the nuclei were stained in blue. Bright yellow fluorescence was a composite image of green and red fluorescence, and used to indicate the targeting effect of the liposomes with integrin $\beta 3$ receptor on MDA-MB-231 cells. Results demonstrated that the functional coumarin liposomes were bound with the integrin $\beta 3$ receptor and exhibited substantially higher green fluorescence intensity in the MDA-MB-231 cells compared with the coumarin liposomes, which suggests that more functional liposomes had been internalized by the cancer cells.

\section{Inhibitory effects and induction of apoptosis on TNBC cells}

Figure 4A illustrates the inhibitory effects of free drugs on MDA-MB-231 cells. Results demonstrated that free vincristine alone had limited efficacy in inhibiting MDA-MB-231 cells; in contrast, in the co-treatment of free vincristine with free dasatinib, the inhibitory effect of vincristine on the cancer cells was significantly enhanced in a dasatinib concentration-dependent manner. Figure 4B demonstrates the inhibitory effects of functional 


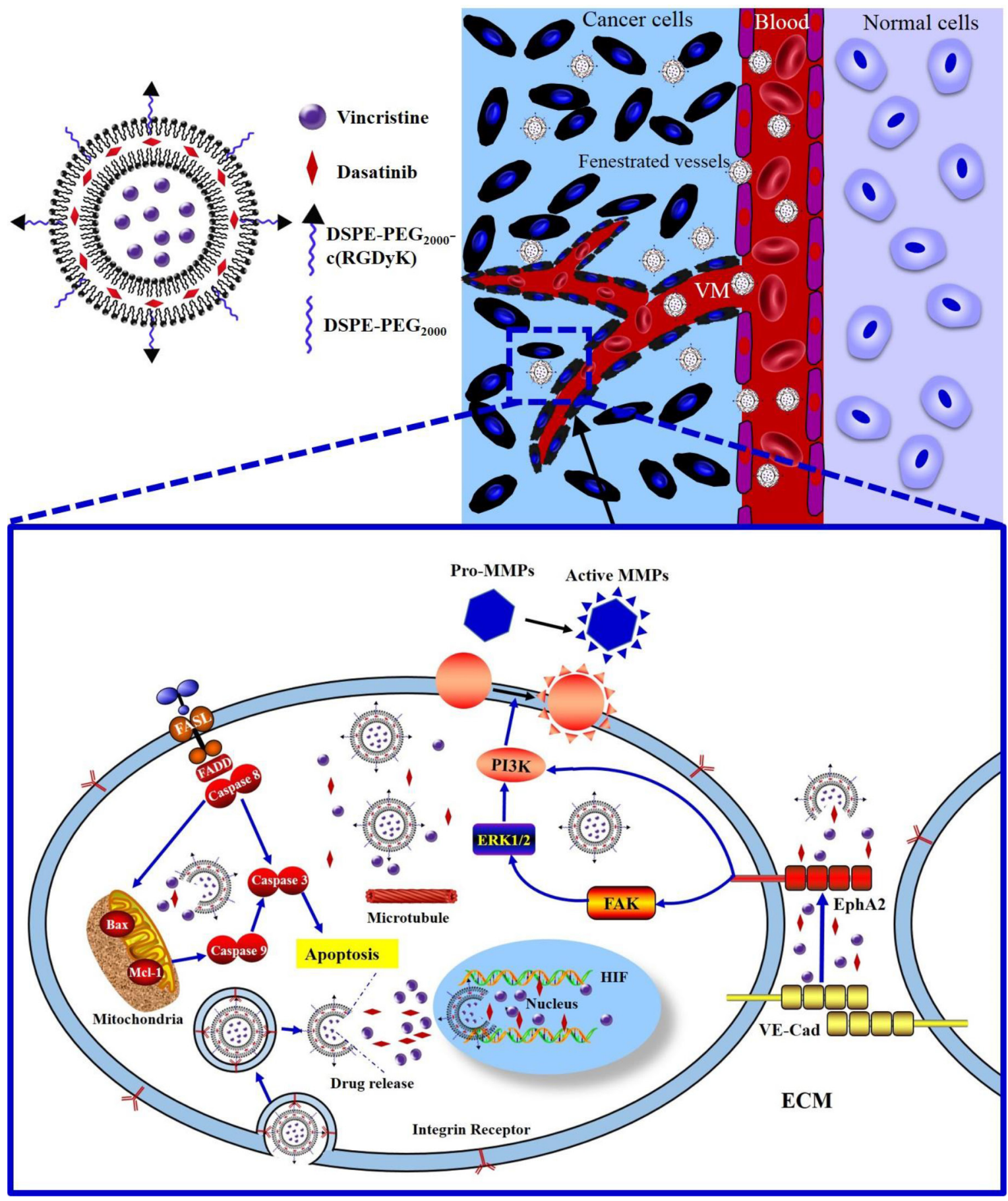

Figure 1: Schematic design and mechanism of functional vincristine plus dasatinib liposomes for the treatment of TNBC and VM channel elimination. Notes: During hypoxic conditions, the transcription of VE-Cad is increased, and EphA2 is subsequently re-localized to the cell membrane and phosphorylated. Phosphorylated EphA2 directly activates PI3K or initiates the activation of FAK and downstream PI3K. Activated PI3K, in turn, activates MMPs (MMP-2 and MMP-9), which eventually results in VM channel formation. Functional vincristine plus dasatinib liposomes specifically bind to integrin receptors on cancer cells. The internalized liposomes induce the apoptosis of cancer cells through a cascade of apoptotic reactions via the activation of caspase 8,9 , and 3 , the increased expression of the pro-apoptotic protein Bax, the decreased expression of anti-apoptotic protein Mcl-1, and generation of ROS. Furthermore, they destroy VM channels via the decreased expression of VE-Cad, FAK, PI3K, MMP-2 and MMP-9.

vincristine plus dasatinib liposomes. Among the four types of liposomes, functional vincristine plus dasatinib liposomes exhibited the strongest inhibitory effects on cancer cells at various dose levels. The blank functional liposomes exhibited a minimal cytotoxic effect toward cancer cells. 


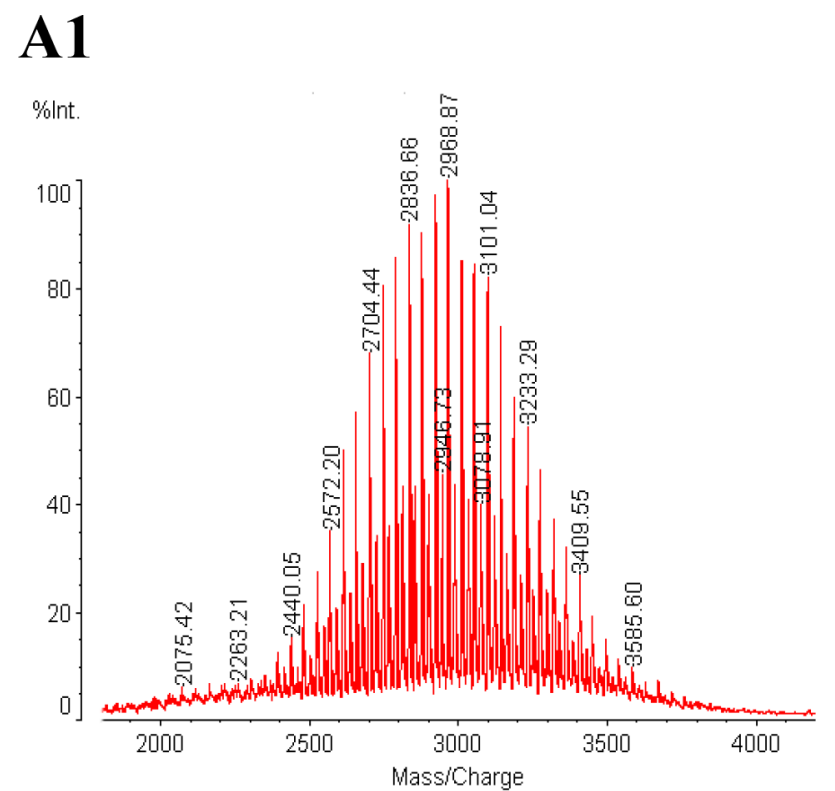

\section{A2}
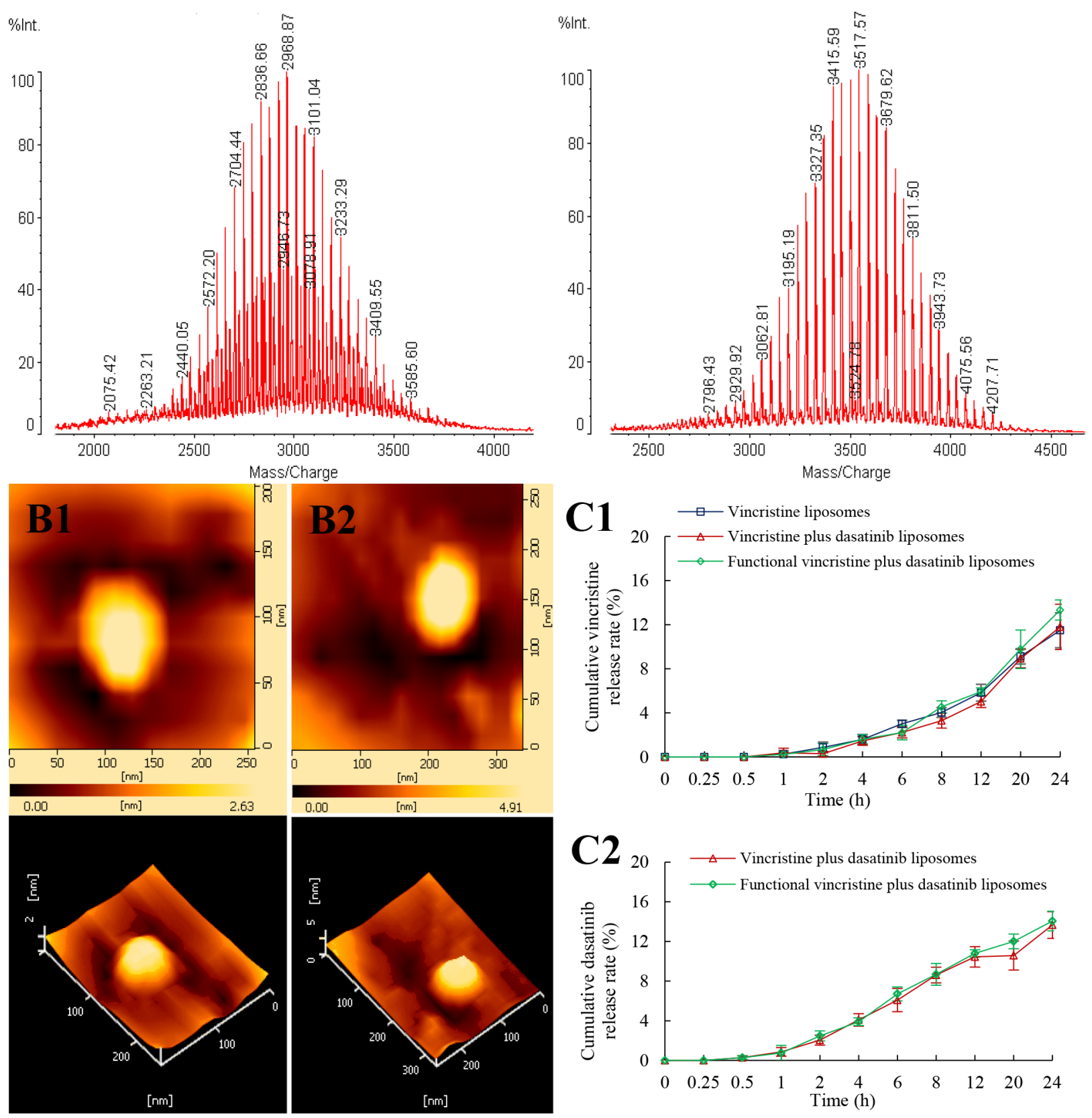

Figure 2: Characterization of targeting molecules and functional vincristine plus dasatinib liposomes. Notes: MALDTOF-MS spectra of (A1) DSPE-PEG 2000 -NHS and (A2) DSPE-PEG ${ }_{2000}$-c(RGDyK) targeting molecule. AFM images of (B1) vincristine liposomes and (B2) functional vincristine plus dasatinib liposomes. Release rates of $(\mathrm{C} 1)$ vincristine and (C2) dasatinib from the liposomes. Data are presented as the mean $\pm \mathrm{SD}(n=3)$.

Figure 4C depicts the induced apoptosis on MDA-MB-231 cells. After incubation with blank medium, vincristine liposomes, vincristine plus dasatinib liposomes and functional vincristine plus dasatinib liposomes, the total percentages of apoptosis were 10.60 $\pm 1.20,18.70 \pm 0.78,22.16 \pm 2.32$ and $31.36 \pm 1.51 \%$, respectively.

\section{Apoptotic signaling pathways of TNBC cells}

Figure 5A displays the expression levels of representative apoptotic enzymes and related apoptotic proteins in cancer cells after treatments with varying formulations. As compared to the blank control, functional vincristine plus dasatinib liposomes significantly increased 
Table 1: Characterization of the liposomes

\begin{tabular}{|c|c|c|c|c|c|}
\hline \multirow[t]{2}{*}{ Liposomes } & \multirow[t]{2}{*}{ Particle size (nm) } & \multirow[t]{2}{*}{ Polydispersity Index } & \multirow[t]{2}{*}{ Zeta potential $(\mathrm{mV})$} & \multicolumn{2}{|c|}{ Encapsulation efficiency (\%) } \\
\hline & & & & vincristine & dasatinib \\
\hline $\begin{array}{l}\text { Blank } \\
\text { functional } \\
\text { liposomes }\end{array}$ & $103.10 \pm 1.54$ & $0.17 \pm 0.01$ & $-5.48 \pm 0.35$ & - & - \\
\hline $\begin{array}{l}\text { Vincristine } \\
\text { liposomes }\end{array}$ & $103.37 \pm 2.27$ & $0.17 \pm 0.01$ & $-8.61 \pm 0.83$ & $97.92 \pm 0.85$ & - \\
\hline $\begin{array}{l}\text { Vincristine } \\
\text { plus dasatinib } \\
\text { liposomes }\end{array}$ & $104.73 \pm 2.02$ & $0.16 \pm 0.03$ & $-8.57 \pm 0.09$ & $98.21 \pm 0.78$ & $93.29 \pm 0.75$ \\
\hline $\begin{array}{l}\text { Functional } \\
\text { vincristine } \\
\text { plus dasatinib } \\
\text { liposomes }\end{array}$ & $104.50 \pm 1.97$ & $0.17 \pm 0.02$ & $-6.21 \pm 0.41$ & $97.72 \pm 0.87$ & $91.79 \pm 0.42$ \\
\hline
\end{tabular}

Data are presented as the mean $\pm \mathrm{SD}(n=3)$.
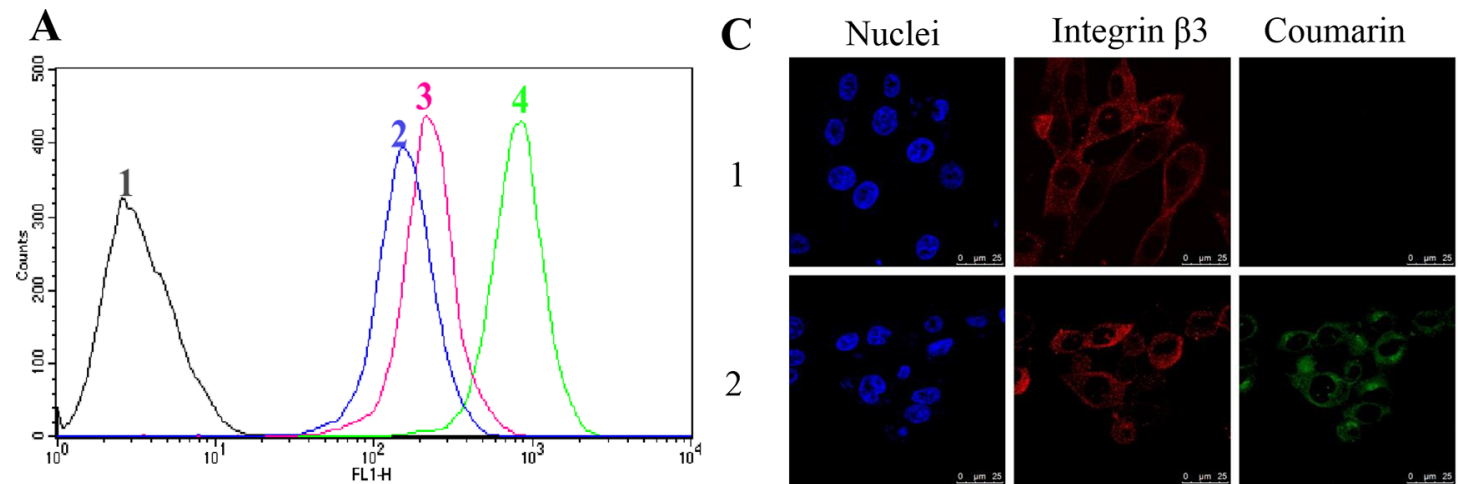

Combined
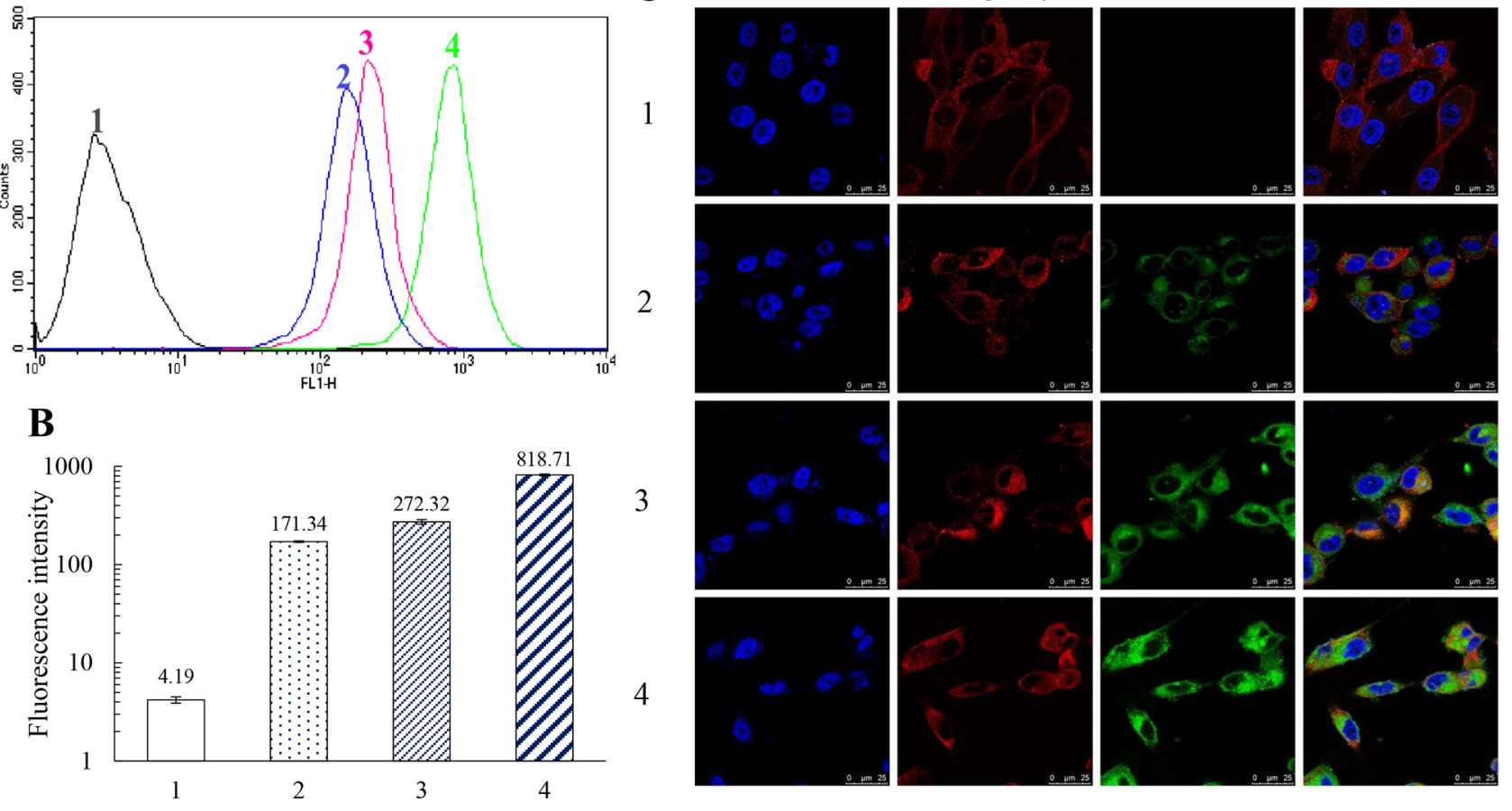

Figure 3: Cellular uptake by MDA-MB-231 cells and targeting effect of functional coumarin liposomes. Notes: A, B. Evaluation of cellular uptake via flow cytometry. Data are presented as the mean $\pm \mathrm{SD}(n=3)$. C. Observation of targeting effect under a confocal microscope (scale bar $=25 \mu \mathrm{m}$ ). 1, blank control; 2, coumarin liposomes; 3, functional coumarin liposomes; 4, free coumarin.

the expression levels of caspase 3, caspase 8, caspase 9, and pro-apoptotic protein Bax while significantly suppressed the expression level of anti-apoptotic protein Mcl-1.

Figure 5B and 5C display the corresponding quantification results of above apoptotic enzymes and proteins. After treatment with blank medium, vincristine liposomes, vincristine plus dasatinib liposomes and functional vincristine plus dasatinib liposomes, the activities of apoptotic enzymes caspase 8,9 , and 3 , the pro-apoptotic protein Bax and the anti-apoptotic protein Mcl-1 were changed in varying discriminable degrees as follows: the activity ratios of caspase 8 were $1.00 \pm 0.02$, $1.05 \pm 0.03,1.10 \pm 0.02$ and $1.16 \pm 0.03$, respectively; the activity ratios of caspase 9 were $1.00 \pm 0.02,1.11 \pm 0.03$, $1.19 \pm 0.04$ and $1.26 \pm 0.01$, respectively; and the 

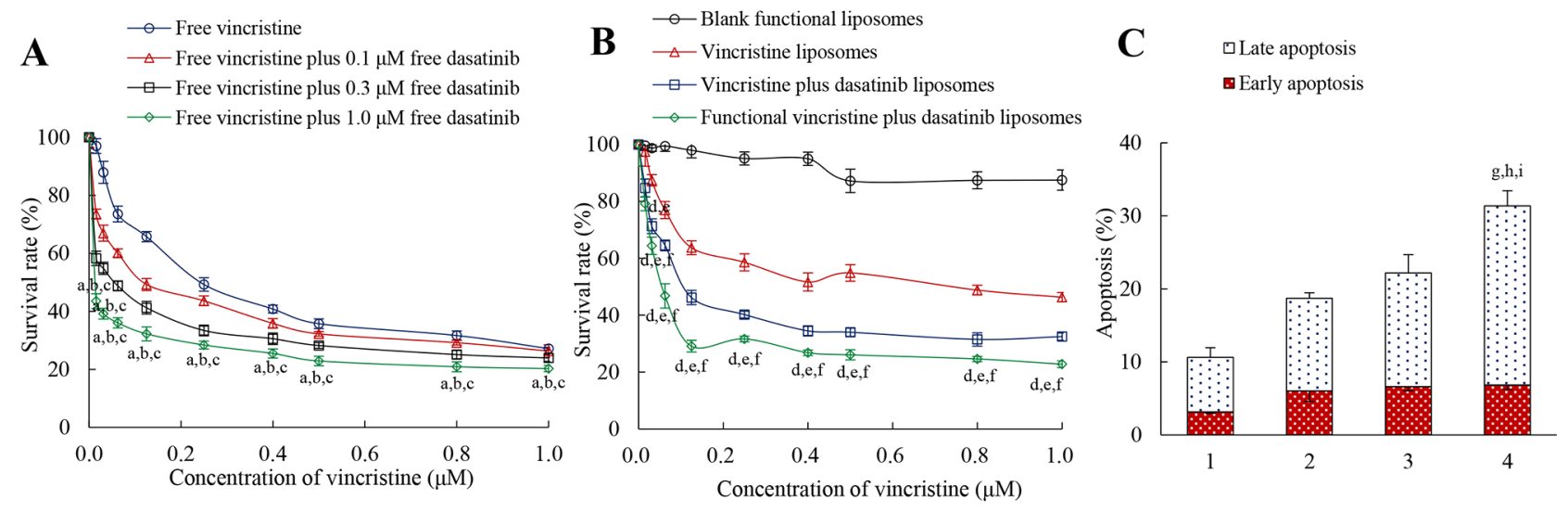

Figure 4: Inhibitory effect and induced apoptosis of MDA-MB-231 cells after treatment with functional vincristine plus dasatinib liposomes. Notes: Inhibitory effects on MDA-MB-231 cells after treatments with A. free drugs and $\mathbf{B}$. varying liposomes for 48 h. $p<0.05$, a, vs. free vincristine; b, vs. free vincristine plus $0.1 \mu \mathrm{M}$ free dasatinib; c, vs. free vincristine plus $0.3 \mu \mathrm{M}$ free dasatinib; $\mathrm{d}$, vs. blank functional liposomes; e, vs. vincristine liposomes; $\mathrm{f}$, vs. vincristine plus dasatinib liposomes. Data are presented as the mean \pm $\mathrm{SD}(n=6)$. C. Induced apoptotic percentages of MDA-MB-231 cells. Data are presented as the mean $\pm \operatorname{SD}(n=3)$. 1, control; 2, vincristine liposomes; 3 , vincristine plus dasatinib liposomes; 4, functional vincristine plus dasatinib liposomes. $p<0.05$, g, vs. 1 ; h, vs. 2 ; i, vs. 3 .

activity ratios of caspase 3 were $1.00 \pm 0.02,1.12 \pm 0.03$, $1.17 \pm 0.02$ and $1.26 \pm 0.02$, respectively. The activity ratios of Bax were $1.00 \pm 0.01,1.07 \pm 0.02,1.14 \pm 0.02$ and $1.20 \pm 0.02$, respectively, and the activity ratios of Mcl-1 were $1.00 \pm 0.03,0.95 \pm 0.03,0.89 \pm 0.01$ and $0.81 \pm 0.04$, respectively.

Figure 5D shows the level of reactive oxygen species (ROS) after treatments with varying formulations. The rank of ROS levels after treatments was functional vincristine plus dasatinib liposomes $>$ vincristine plus dasatinib liposomes $>$ vincristine liposomes $>$ blank medium.

\section{Destruction of VM channels of TNBC cells}

Figure 6A displays the destructive effect on VM channels in a three dimensional matrigel culture model after treatments with varying formulations. The highly invasive MDA-MB-231 cells formed vessel-like loops, channels and networks after treatment with blank medium. The VM networks were significantly damaged after treatment with functional vincristine plus dasatinib liposomes, which exhibited the strongest destructive effect on the VM channels compared with other formulations.

Figure $6 \mathrm{~B}$ to $6 \mathrm{~F}$ illustrate the effects of varying formulations on the expressions of vascular endothelial-cadherin (VE-Cad), focal adhesion kinase (FAK), phosphatidylinositide 3-kinase (PI3K), and matrix metallopeptidases (MMP-2, and MMP-9) in MDA-MB-231 cells. After drug treatments, the inhibitory effects were evidenced by the expression ratios, which were ranked as follows: blank medium $>$ vincristine liposomes $>$ vincristine plus dasatinib liposomes $>$ functional vincristine plus dasatinib liposomes. The functional vincristine plus dasatinib liposomes significantly inhibited the expression of VM indicators. The inhibition of these indicators for forming VM channels would facilitate the elimination of VM channels in TNBC treatment.

\section{Destruction of TNBC tumor spheroids}

Figure 7A exhibits the penetration ability of coumarin-labeled liposomes into tumor spheroids. After incubation with varying formulations, images were taken in each layer of the spheroids. Results showed that the rank of fluorescent intensities in the spheroids was functional coumarin liposomes $>$ free coumarin $>$ coumarin liposomes, indicating that the functional liposomes had the strongest penetrating ability.

Figure $7 \mathrm{~B}$ represents the destructive efficacy to tumor spheroids. After treatments with varying liposomes, functional vincristine plus dasatinib liposomes caused the most significant destructive effects, as the tightly organized spheroids were disintegrated.

Figure 7C displays the inhibitory effect on tumor spheroids. After treatment with blank medium, vincristine liposomes, vincristine plus dasatinib liposomes and functional vincristine plus dasatinib liposomes, the spheroid volume change ratios at day 5 were $2.14 \pm 0.29$, $1.27 \pm 0.12,1.17 \pm 0.17$ and $0.77 \pm 0.08$, respectively. Among these results, functional vincristine plus dasatinib liposomes exhibited the most significant inhibitory effects on tumor spheroid growth.

\section{Anticancer efficacy}

Figure 8A1 indicates the anticancer efficacy in tumor-bearing mice xenografted with MDA-MB-231 cells. Using physiological saline as a blank control, the inhibitory ratios of the tumor volumes at day 25 were 

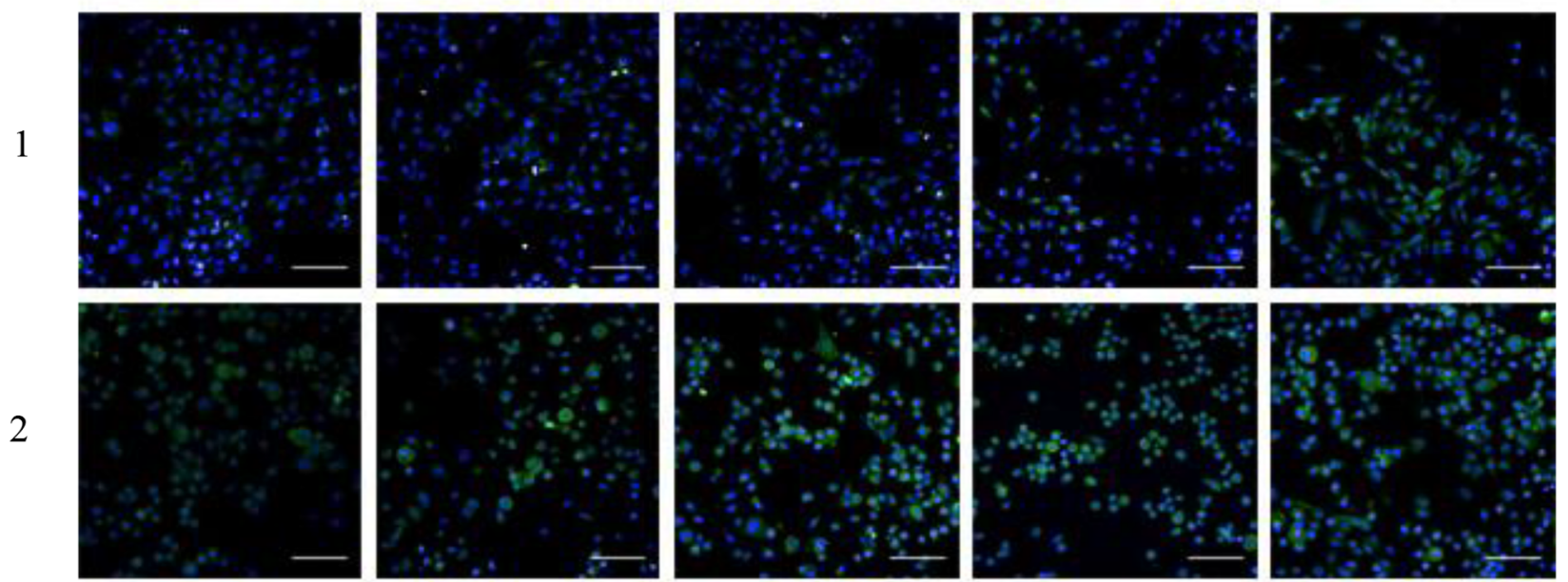

2
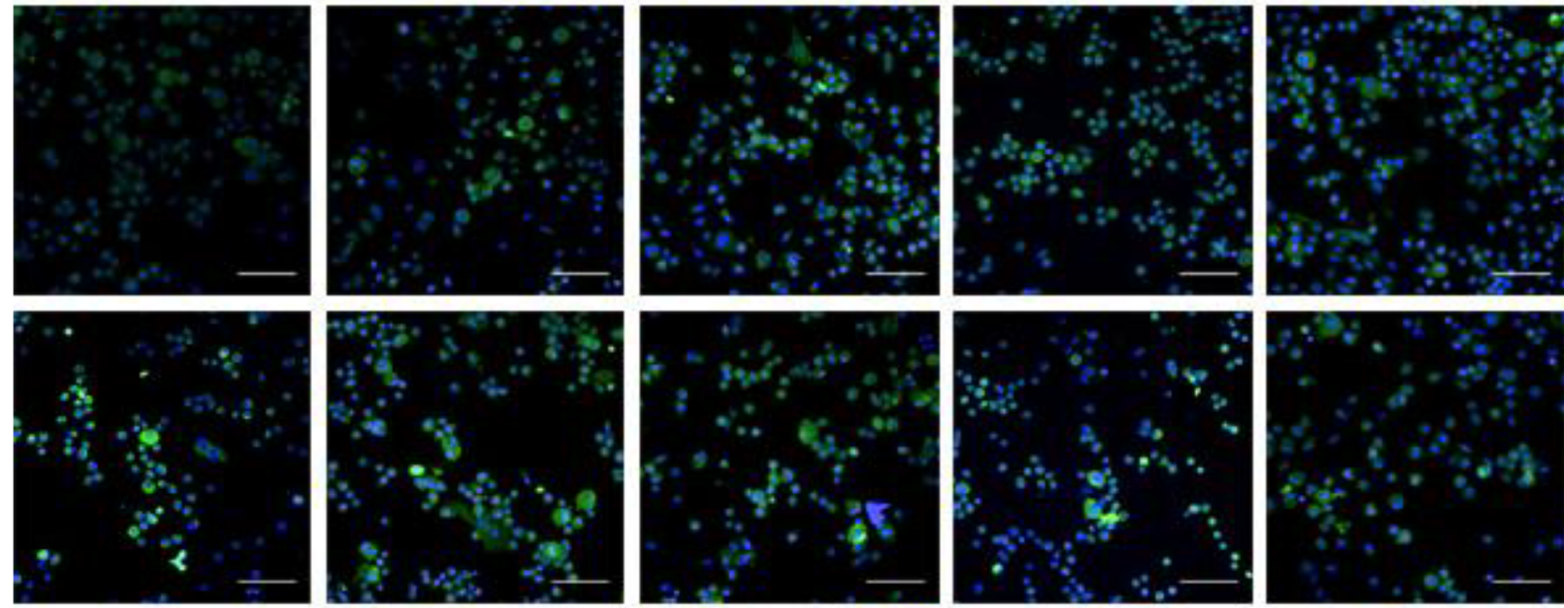

4
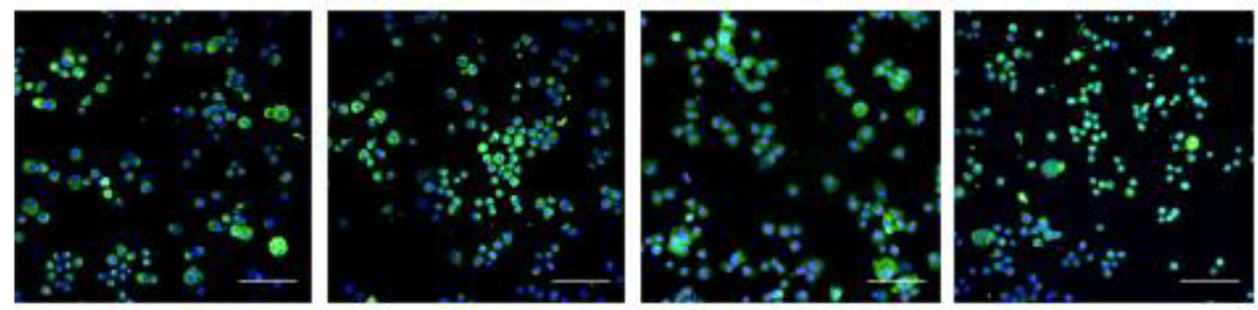

B

$\square 1 \square 2 \quad 3 \quad \square 4$

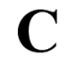

$\square 1 \quad \square 2 \quad \square 3 \quad \square 4$
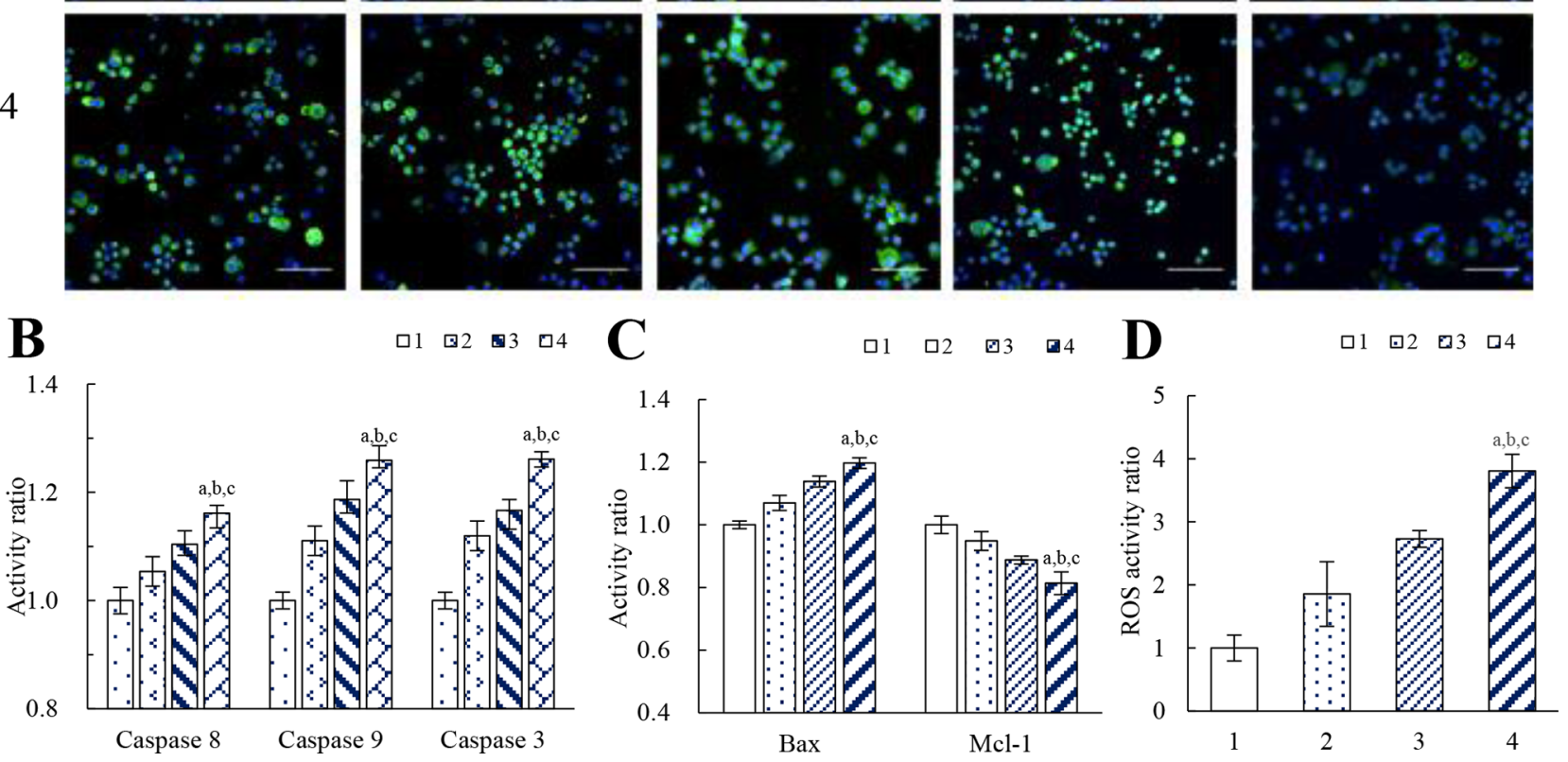

Figure 5: Effects on apoptotic enzymes, apoptotic proteins and ROS level of MDA-MB-231 cells after treatment with functional vincristine plus dasatinib liposomes. Notes: A. Fluorescent images of the expressed apoptotic enzymes and apoptotic proteins (scale bar $=100 \mu \mathrm{m}$ ). B. Activity ratios of caspase 8, caspase 9 and caspase 3. C. Activity ratios of Bax and Mcl-1. Data are presented as the mean $\pm \operatorname{SD}(n=6)$. D. ROS activity ratio. Data are presented as the mean $\pm \operatorname{SD}(n=3)$. 1, blank control; 2, vincristine liposomes; 3, vincristine plus dasatinib liposomes; 4, functional vincristine plus dasatinib liposomes. $p<0.05$, a, vs. 1; b, vs. 2 ; c, vs. 3 .

$19.31 \pm 9.22 \%$ for free vincristine, $41.01 \pm 5.35 \%$ for vincristine liposomes, $52.66 \pm 5.39 \%$ for vincristine plus dasatinib liposomes, and $66.00 \pm 4.04 \%$ for functional vincristine plus dasatinib liposomes. These findings indicate that the functional vincristine plus dasatinib liposomes had the strongest overall anticancer efficacy among the different formulations.

The efficacy of VM channel elimination was evaluated using the periodic acid-Schiff (PAS)-CD34 dual staining assay, and the VM channels were stained in red in the tumor 

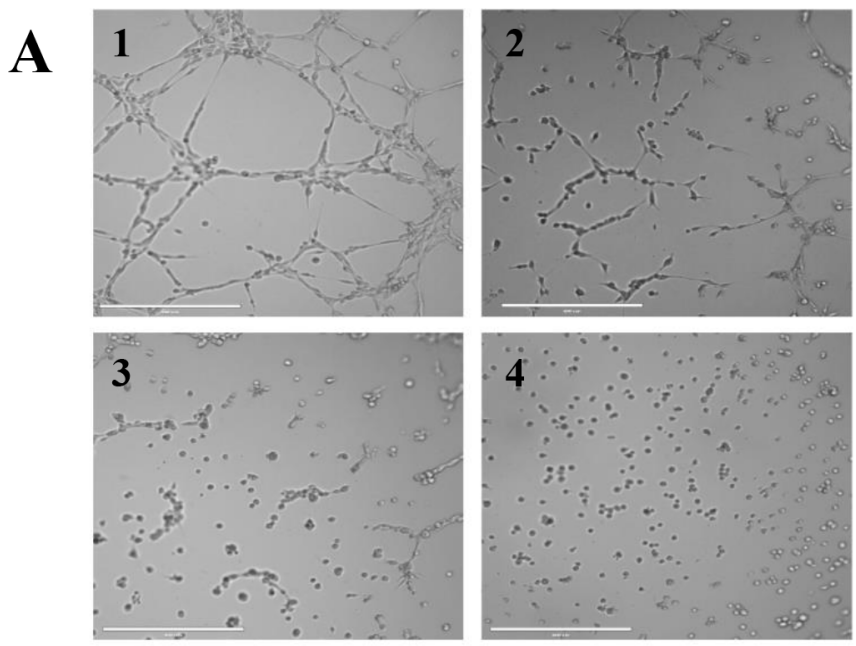

C
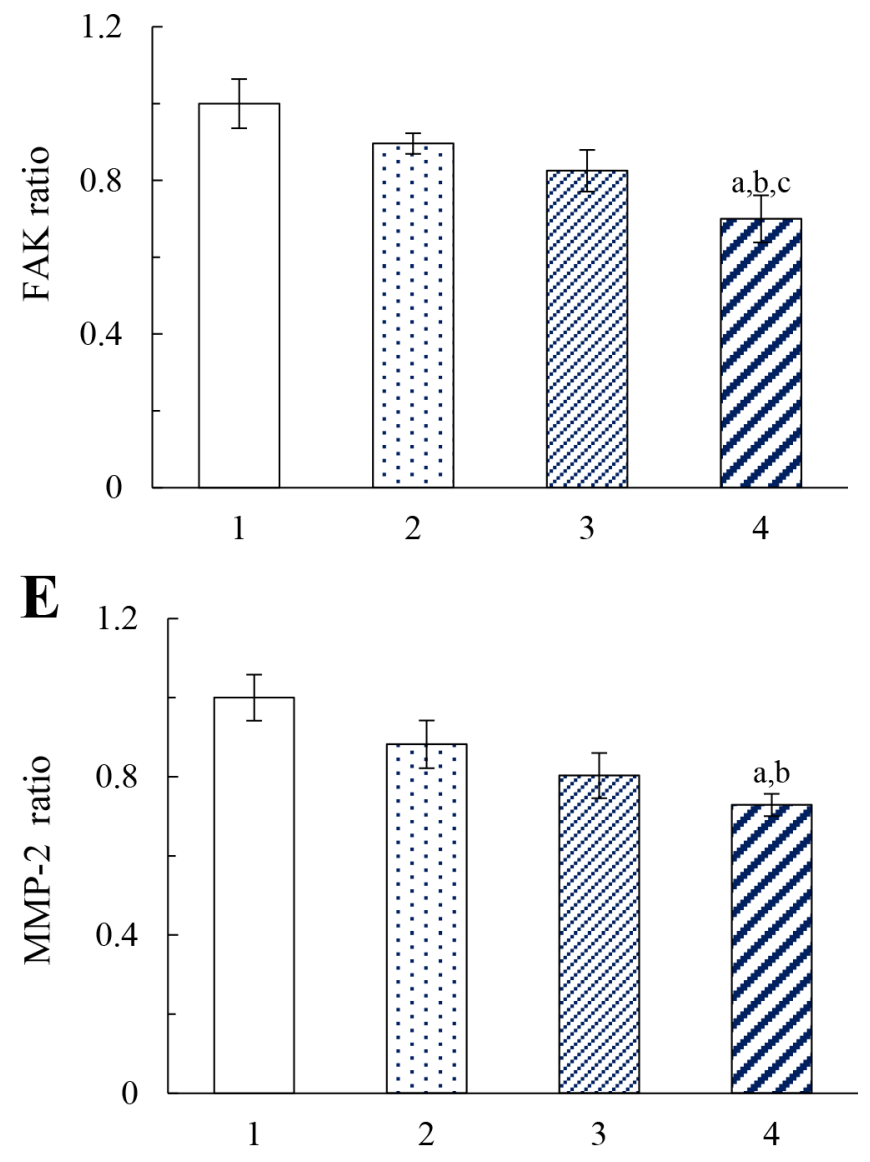

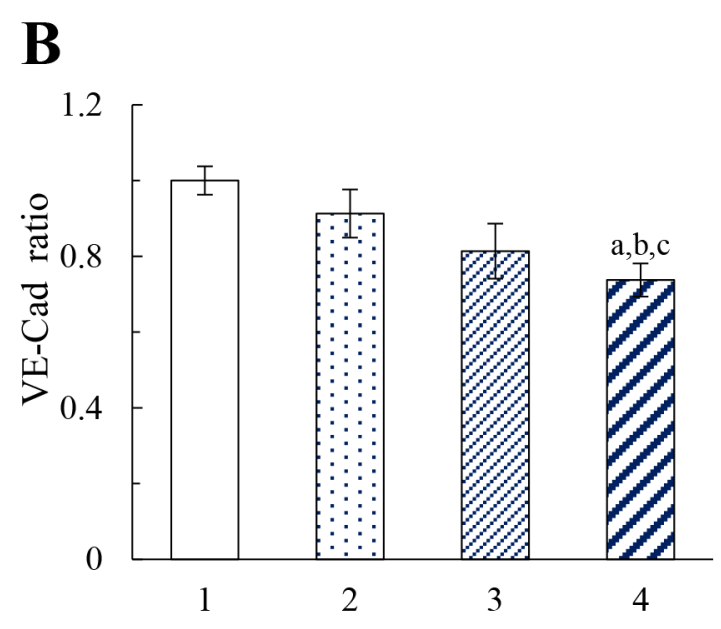

D

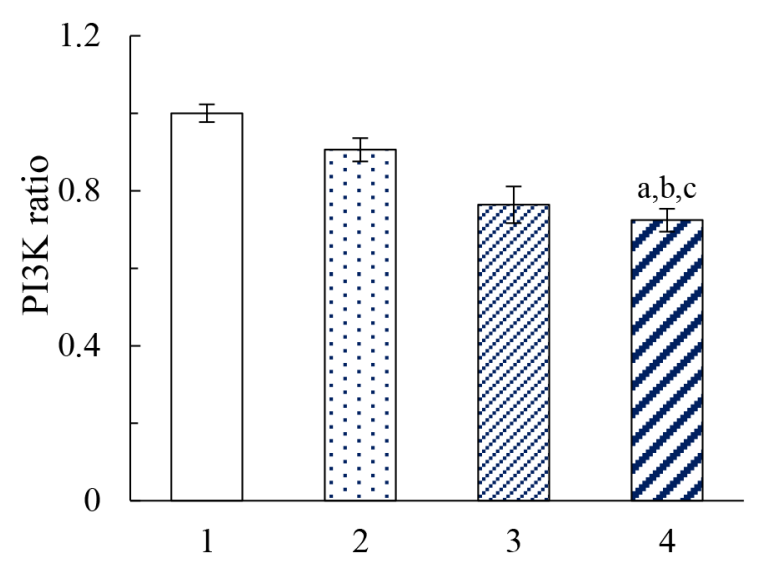

F

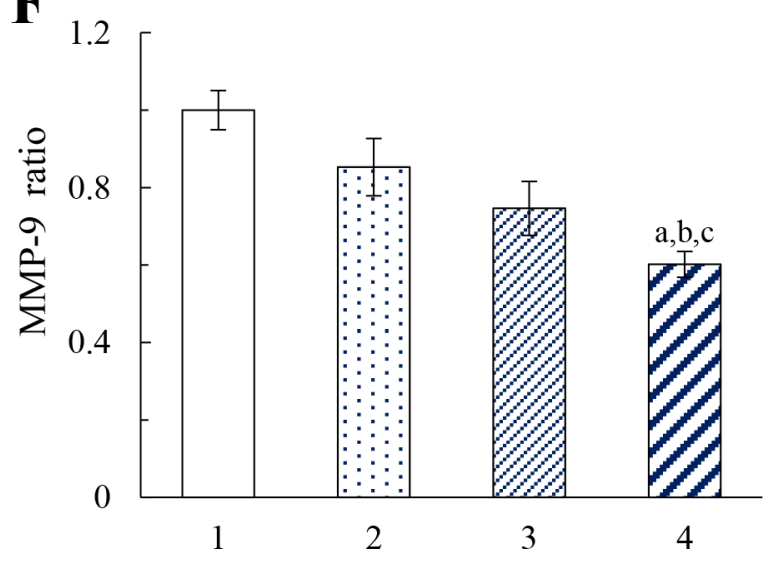

Figure 6: Destructive effects on the VM channels of MDA-MB-231 cells after treatment with functional vincristine plus dasatinib liposomes. Notes: A. Destructive effects on the VM channels. Inhibitory effects on the VM channel indicators, including B. VE-Cad, C. FAK, D. PI3K, E. MMP-2, and F. MMP-9. Data are presented as the mean \pm SD $(n=3)$. 1, blank control; 2, vincristine liposomes; 3 , vincristine plus dasatinib liposomes; 4, functional vincristine plus dasatinib liposomes. $p<0.05$, a, vs. 1; b, vs. 2 ; c, vs. 3.

slices. After treatment, the rank of VM channel numbers in the tumor slices was physiological saline $>$ free vincristine $>$ vincristine liposomes $>$ vincristine plus dasatinib liposomes $>$ functional vincristine plus dasatinib liposomes (Figure 8B).

Figure $8 \mathrm{C}$ displays the induced apoptosis in the tumor tissue assessed using a terminal deoxynucleotidyl transferase-mediated dUTP nick end labeling (TUNEL) assay. The apoptotic cancer cells were displayed with green fluorescence under the confocal microscope. After treatment, functional vincristine plus dasatinib liposomes resulted in the most evident apoptosis of cancer cells compared with other controls. 


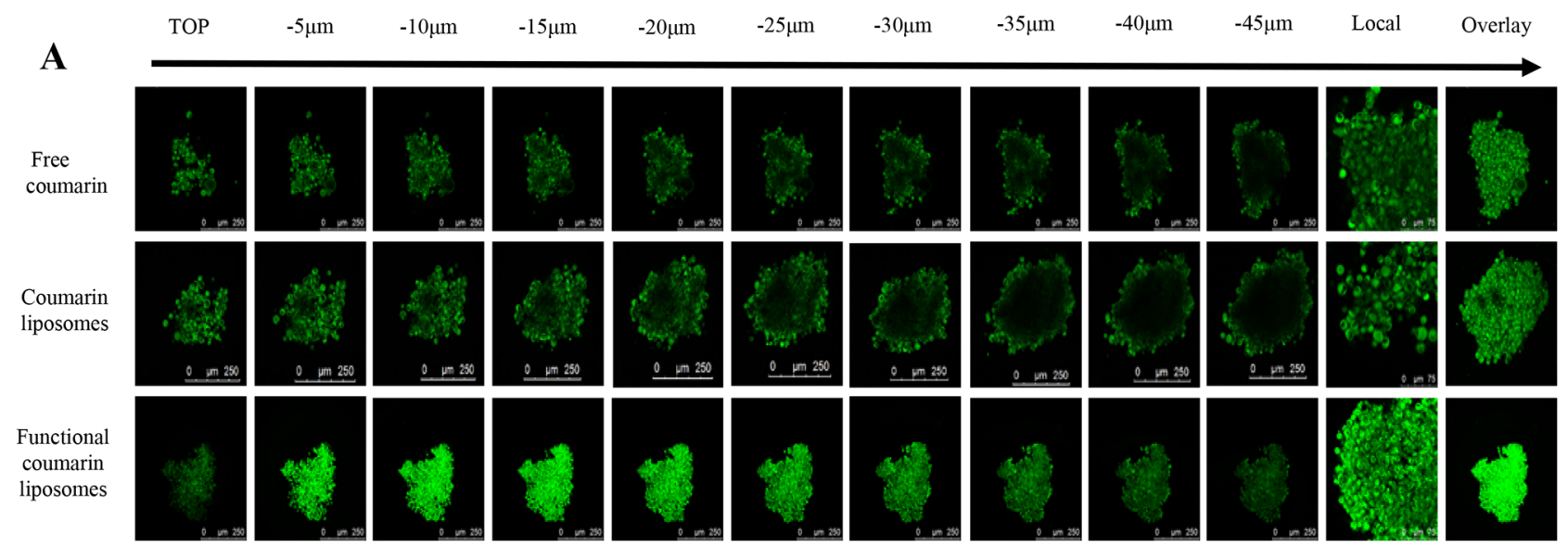

B
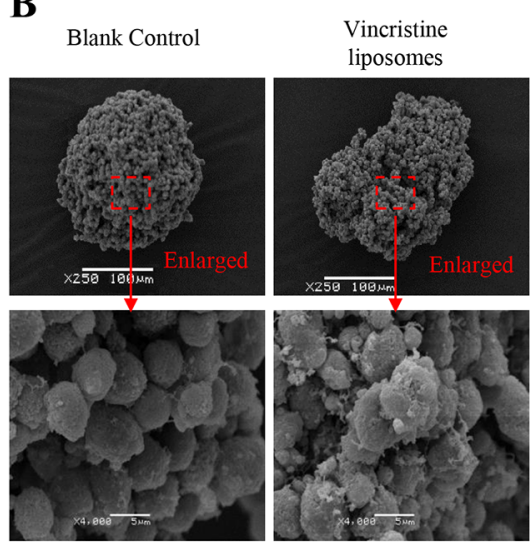

Vincristine plus

Functional vincristine plus dasatinib liposomes
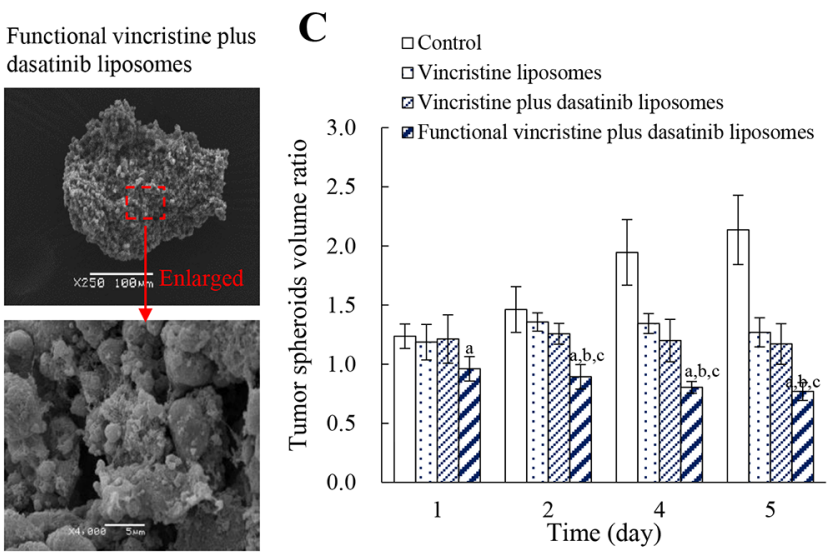

Figure 7: Penetrating ability and destructive effects on the tumor spheroids of MDA-MB-231 cells after treatment with functional liposomes. Notes: A. Penetrative ability of functional liposomes to the spheroids (scale bar $=250 \mu \mathrm{m}$ ). B. Destructive effect on the spheroids (scale bar $=100 \mu \mathrm{m}$ ). C. Inhibitory effect on spheroid growth. Data are presented as the mean $\pm \operatorname{SD}(n=6)$. $p<0.05$, a, vs. blank control; b, vs. vincristine liposomes; c, vs. vincristine plus dasatinib liposomes.

In addition, the preliminary systemic toxicities after the treatments were evaluated via the body weight, blood examination and histopathological observation of major organs. Compared with physiological saline, there were no significant weight changes (Figure 8A2) or abnormalities in blood indicators (Supplementary Table S1) or major organs (heart, liver, spleen, lung, and kidney) (Figure 8D) after treatment with functional vincristine plus dasatinib liposomes.

\section{In vivo imaging in mice}

Figure 9A depicts the real-time imaging and distribution of drug-loaded liposomes in tumor-bearing mice xenografted with MDA-MB-231 cells. Observations indicated that the functional DiR liposomes maintained longer circulation in the blood system and exhibited a higher accumulation in tumor tissues, for up to $48 \mathrm{~h}$. In contrast, the fluorescent signal in tumor tissues gradually decreased at $12 \mathrm{~h}$ after treatment with DiR liposomes, whereas the fluorescent signal rapidly accumulated in the liver after treatment with free DiR.
Figure 9B illustrates the ex vivo optical images of tumor masses and major organs after the mice were sacrificed. Results showed that the fluorescent signals remained clearly visible in the tumor masses after treatment with functional DiR liposomes. In comparison, the fluorescent signals in the tumor masses were weakly visible after treatment with DiR liposomes and invisible after treatment with free DiR or physiological saline. In addition, strong fluorescent signals were identified in the livers and spleens after treatment with all DiR formulations.

\section{DISCUSSION}

The residual aggressive cancer cells of TNBC can form the VM channels by self-transforming to support further growth of cancer tissue, leading to relapse and metastasis of the cancer. The VM channels are detected in clinical breast cancer specimens and associated with a poor 5 -year survival rate [23-25]. Therefore, the functional vincristine plus dasatinib liposomes were developed 
for treatment of TNBC along with deletion of the VM channels.

In the functional liposomes, vincristine was encapsulated into the inner vesicle, and dasatinib was incorporated into the lipid bilayer of DSPE-PEG ${ }_{2000^{-}}$ c(RGDyK) modified liposomes. The liposomes exhibited good characterizations of small and well-distributed particle size, high encapsulation efficiencies (Table 1), smooth surface (Figure 2B2) and delayed drug release (Figure 2C). The particle size is suitable to avoid kidney filtration but allows to be accumulated into cancer tissues via EPR effects [26]. This delayed drug release is beneficial to prevent rapid leakage during circulation in the blood system and increase drug accumulation in cancer tissues.

TNBC cells and VM-capable cancer cells are drugresistant, and the improvement of cellular uptake is the first step to enhance their efficacy. To address this issue, $\mathrm{c}(\mathrm{RGDyK})$ peptide was used as a targeting molecule for binding with the integrin receptor overexpressed on these cells. In evaluating cellular uptake (Figure $3 \mathrm{~A}$ and $3 \mathrm{~B}$ ), the results demonstrate that the fluorescent intensity of functional coumarin liposomes is clearly stronger than the unmodified liposomes, which indicates the increased cellular uptake by cancer cells. Moreover, free coumarin also exhibits clear ingestion by cancer cells because of its direct contact permeation. The targeting effect is observed with a confocal microscope (Figure 3C). After incubation with functional liposomes, a bright yellow fluorescence was observed, indicating the targeting effect of functional liposomes with integrin $\beta 3$ receptor on MDA-MB-231 cells.

In the inhibitory effects assay (Figure 4A), stronger inhibitory effects are observed after co-treatment of free vincristine with free dasatinib, indicating that dasatinib can enhance anticancer effects possibly by inducing apoptosis of cancer cells. Compared with other liposomes,
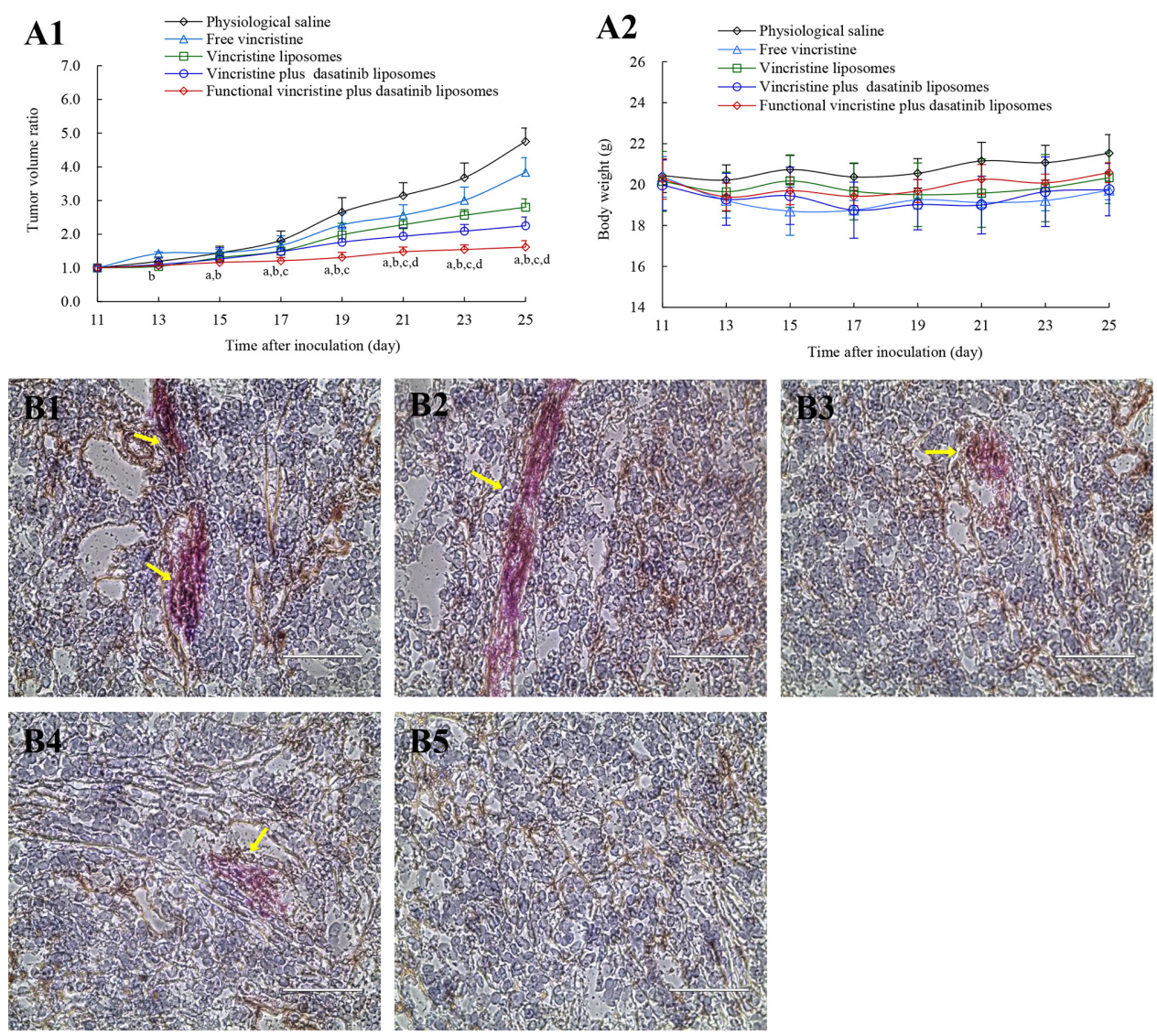

Figure 8: Antitumor efficacy in tumor-bearing nude mice xenografted with MDA-MB-231 cells after treatment with functional vincristine plus dasatinib liposomes. Notes: Tumor volume ratio A1. and body weight changes A2. after treatments. Data are presented as the mean $\pm \mathrm{SD}(n=6) . p<0.05$, a, vs. saline; $\mathrm{b}$, vs. free vincristine; $\mathrm{c}$, vs. vincristine liposomes; d, vincristine plus dasatinib liposomes. The destructive effect on the VM channels in nude mice after treatments with B1. physiological saline, B2. free vincristine, B3. vincristine liposomes, B4. vincristine plus dasatinib liposomes, and B5. functional vincristine plus dasatinib liposomes.

(Continued) 
functional vincristine plus dasatinib liposomes exhibit the strongest inhibitory effects on MDA-MB-231 cells (Figure 4B). This is attributed to the increased cellular uptake by the targeted action.

Apoptosis is a process of programmed cell death involved in cellular stress [27]. In this study, functional vincristine plus dasatinib liposomes exhibited the strongest inducing effects via the activation of caspases 8,9 , and 3 and the pro-apoptotic protein Bax or the suppression of the anti-apoptotic protein $\mathrm{Mcl}-1$ (Figure 5A to 5C). The activation effect on caspase 8 and caspase 9 demonstrate the involvement of the death receptor signaling pathway and the mitochondrial signaling pathway during apoptosis, respectively [28-31]. As upstream initiators of apoptosis, activated caspases 8 and 9 initiate the activation of the downstream effector caspase 3 , which leads to a cascade of apoptotic reactions in the cancer cells [32]. When being activated, pro-apoptotic protein Bax forms dimers and permeabilizes the mitochondrial outer membrane, thereby inducing apoptosis $[33,34]$. In contrast, the anti-apoptotic protein Mcl-1 neutralizes the activity of pro-apoptotic proteins, and ultimately retard apoptotic reactions [35]. Under the induction of functional vincristine plus dasatinib liposomes, the balance slants to promote apoptotic reactions by increasing Bax activity and suppressing Mcl-1 activity.

Appropriate level of ROS plays important role in keeping redox balance and cell proliferation under physiological conditions [36]. However, under oxidative stress conditions, excess ROS exhibit a cytotoxic nature. Excessive ROS levels in MDA-MB-231 cells were produced by treatment with functional vincristine plus dasatinib liposomes (Figure 5D), and the generated ROS could be involved in mitochondrial membrane damage and cytochrome $\mathrm{C}$ release, which induce apoptosis as well [37]. Besides, the greater ROS levels also cause acute injury by necrosis, which thus increases the overall cytotoxicity in the cancer cells.

Under hypoxic conditions, phenotype-transformed invasive cancer cells can form VM channels after treatment [38]. The functional vincristine plus dasatinib liposomes displayed the strongest destructive effect on VM channels (Figure 6A) through the increased cellular uptake, the induced apoptosis and the inhibited marker molecules. During VM channel formation, VE-Cad transcription is increased, and tyrosine kinase

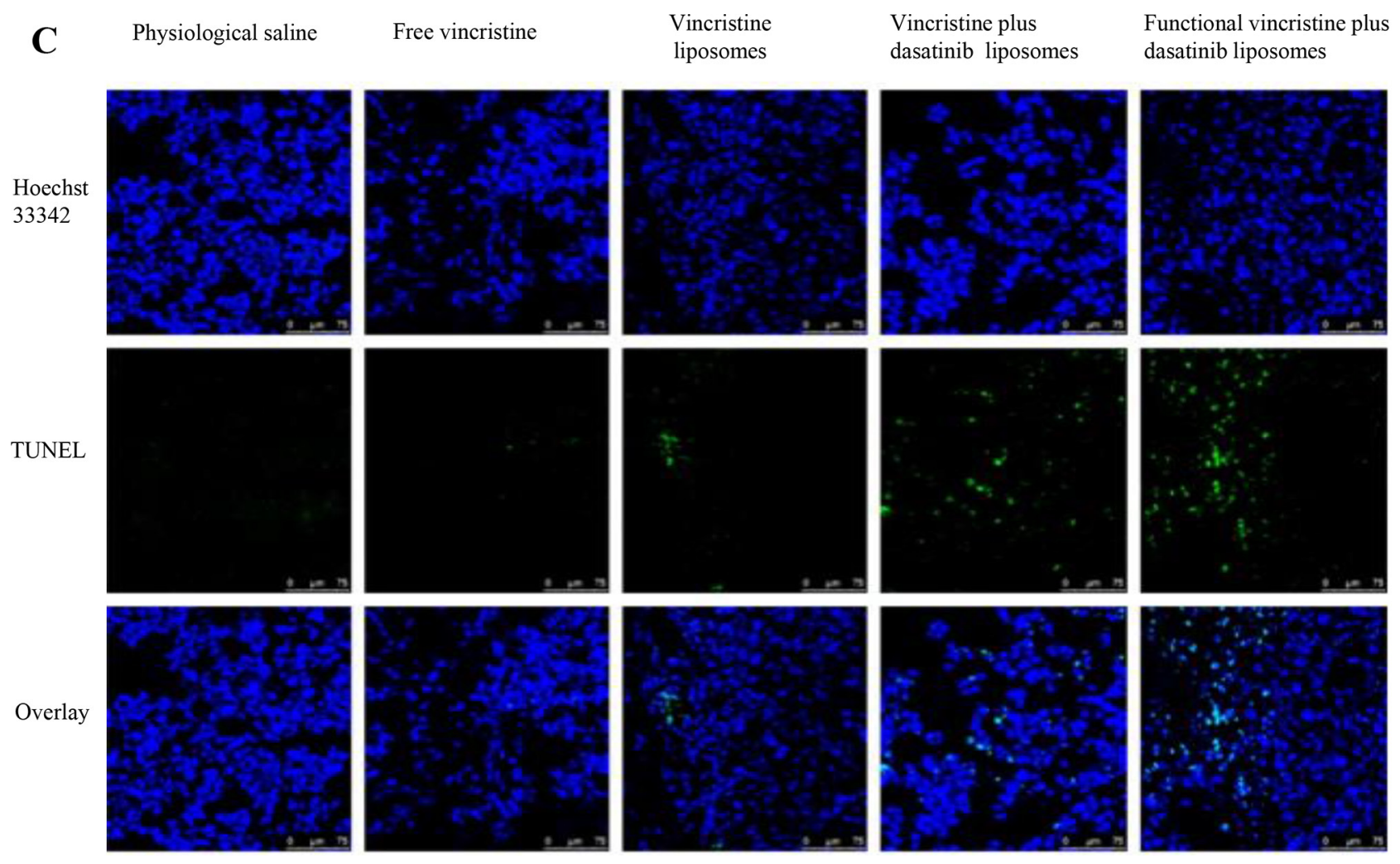

Figure 8: (Continued) C. TUNEL assay of the tumor tissues after treatments of varying formulations (scale bar $=75 \mu \mathrm{m}$ ).

(Continued) 


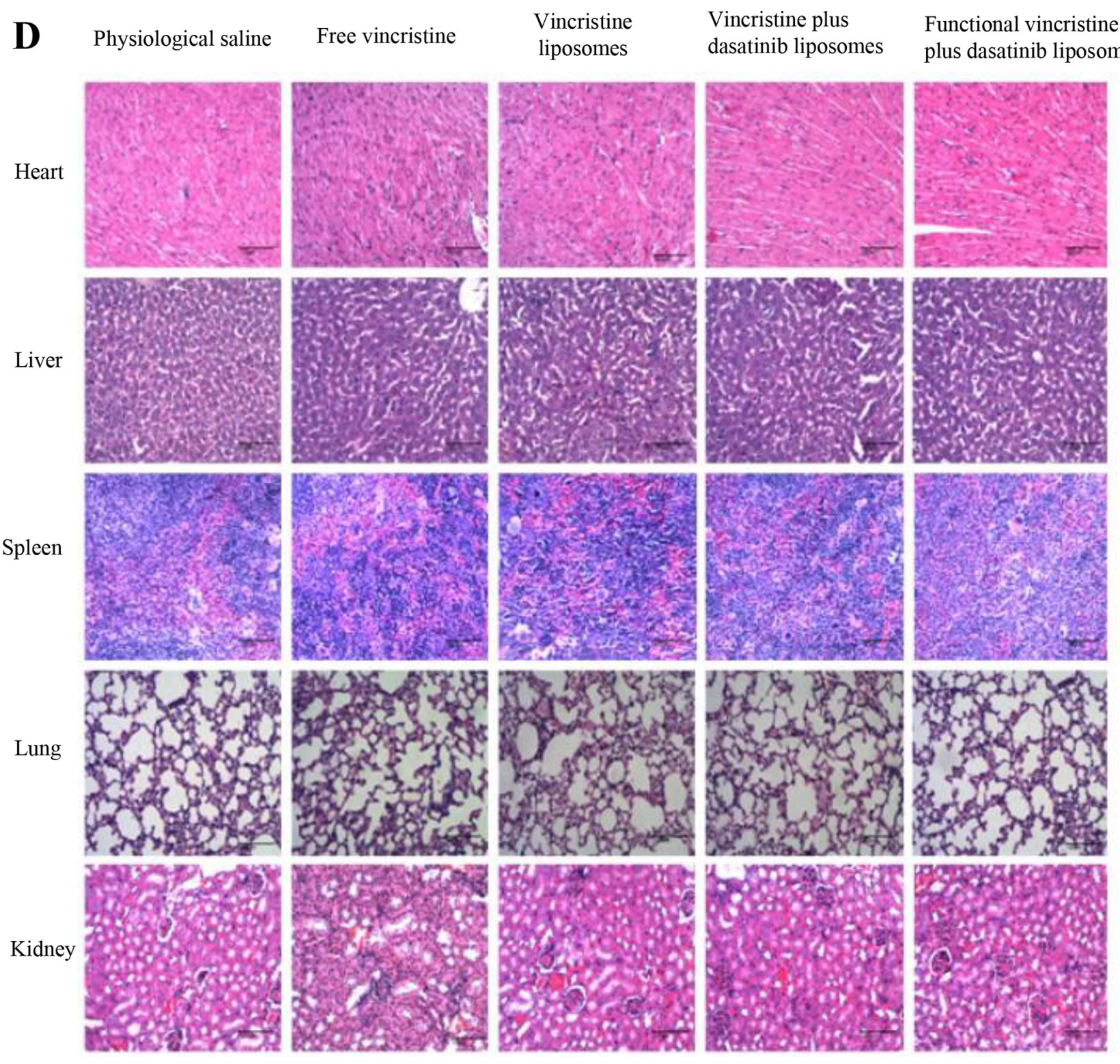

Figure 8: (Continued) D. Histopathological observations of the heart, kidney, liver, lung, and spleen of tumor-bearing nude mice xenografted with MDA-MB-231 cells after treatments of varying formulations (scale bar $=100 \mu \mathrm{m}$ ).

receptor A2 (EphA2) is subsequently re-localized to the cell membrane and phosphorylated. The activated EphA2 proteins promote the localization of FAK to new focal adhesion sites and subsequently activate $\mathrm{PI} 3 \mathrm{~K}$, which thus triggers cell migration and VM channel formation. In addition, the activated VE-Cad and EphA2 proteins also directly activate PI3K, which then promotes the MMP precursor to form MMPs, ultimately promoting the cancer cell binding to form VM channels. After treatments with functional vincristine plus dasatinib liposomes, the expressions of these protein indicators were significantly decreased (Figure 6B to 6F), suggesting a destroying effect on the VM channels, hence being beneficial for eradicating the TNBC.
Multicellular TNBC tumor spheroids were used to simulate a solid tumor environment [39]. Results demonstrated that the functional coumarin liposomes show a strong penetrating ability (Figure 7A), and the functional vincristine plus dasatinib liposomes exhibit a strong destructing efficacy (Figure 7B and 7C). These results indicated the roles of functional vincristine plus dasatinib liposomes in potentially treating refractory solid TNBC with a strong penetrating ability and a destructing efficacy.

The in vivo study was evaluated on tumor-bearing mice from several aspects: anticancer efficacy, induction of apoptosis, VM channels elimination and safety evaluation. The functional vincristine plus dasatinib liposomes exhibited the strongest overall anticancer efficacy 


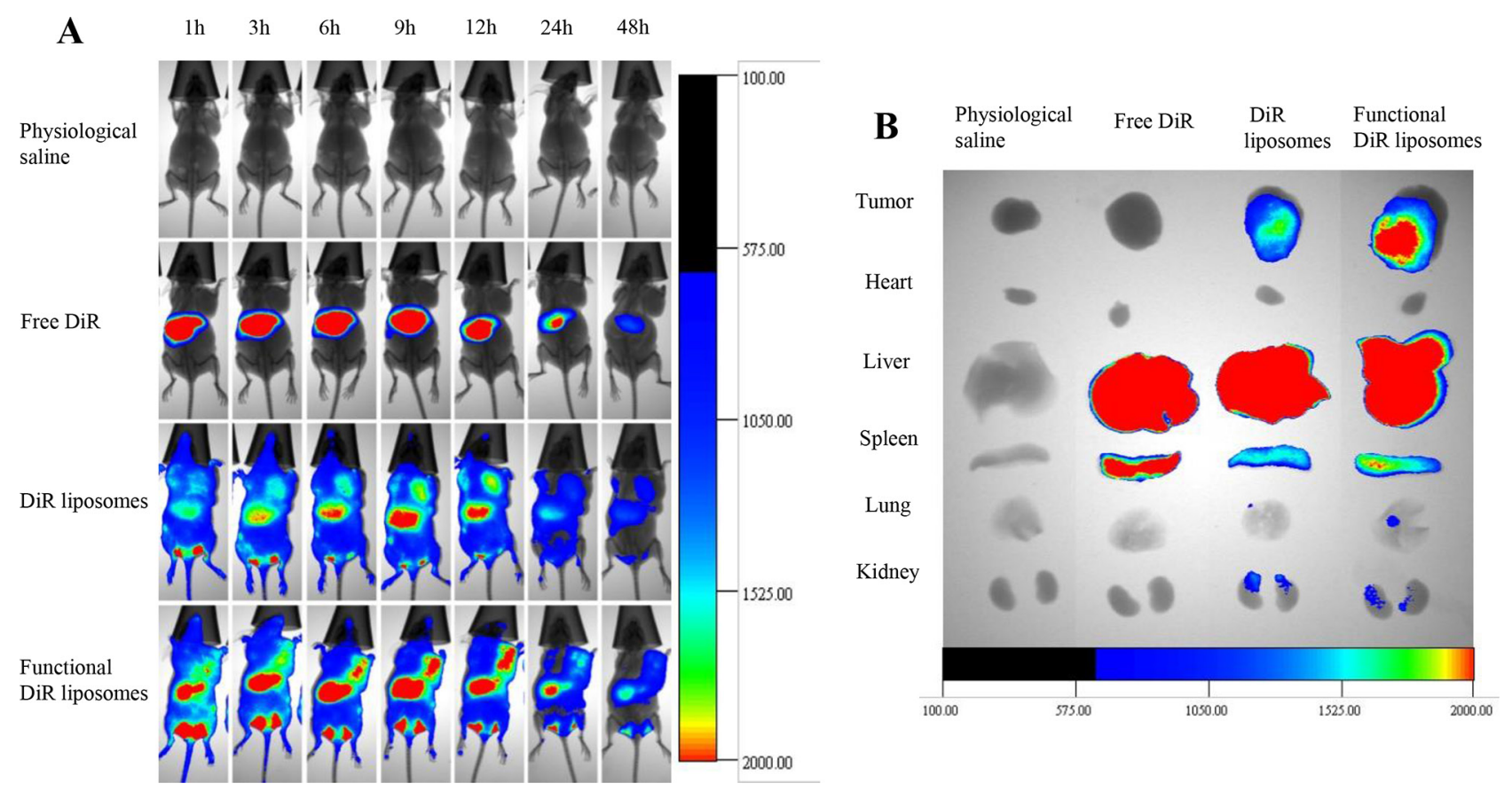

Figure 9: In vivo real-time imaging observation in nude mice after treatment with functional liposomes. Notes: A. In vivo real-time imaging of the tumor-bearing nude mice. B. Ex vivo optical images of the tumor and normal tissues after the tumor-bearing mice sacrificed at $48 \mathrm{~h}$.

(Figure 8A1), elimination of VM channels (Figure 8B) and induction of apoptosis (Figure 8C) in tumor tissues. The enhanced efficacy could be explained as follows: the pegylated liposomes showed a long circulatory effect (Figure 9) by escaping from the rapid clearance by RES in blood circulation [40]; the suitable particle size of the liposomes allows for more accumulation in tumor tissue (Figure 9) by EPR effects; functional liposomes could improve the cytotoxic effects on cancer cells by the increased cellular uptake; and the combination therapy of vincristine and dasatinib enhances the apoptosis and eliminate the VM channels by inhibiting VM indicators.

\section{MATERIALS AND METHODS}

\section{Materials and reagents}

DSPE-PEG $_{2000}$ and DSPE-PEG ${ }_{2000}-\mathrm{NHS}$ were obtained from the NOF Corporation (Tokyo, Japan). The cyclic RGD peptide (c(RGDyK)) was synthesized by GL Biochem Co., Ltd. (Shanghai, China). Vincristine sulfate and dasatinib were supplied by Nanjing Tianzun Zezhong Chemicals, Co., Ltd. (Nanjing, China). Other chemicals were analytical or high performance liquid chromatography grade.

\section{Cancer cells and animal experimentation}

Human breast cancer MDA-MB-231 cells were purchased from the Institute of Basic Medical Science, Chinese Academy of Medical Science (Beijing, China).
Cells were grown in Leibovitz's L15 medium (Macgene, Beijing, China) supplemented with $10 \%$ fetal bovine serum (FBS, Gibco, Billings, USA) in a $37^{\circ} \mathrm{C}$ humidified incubator. Female BALB/c nude mice (initial weight of 16-18 g) were obtained from the Peking University Experimental Animal Center (Beijing, China). All animal experimental procedures were performed with the approval of the Institutional Authority for Laboratory Animal Care of Peking University according to the guidelines.

\section{Synthesis of targeting molecules}

DSPE-PEG $_{2000}-\mathrm{c}(\mathrm{RGDyK})$ conjugate was synthesized via the following procedures. Briefly, $\mathrm{c}(\mathrm{RGDyK})$ peptide and DSPE-PEG $2000-\mathrm{NHS}$ were dissolved at a ratio of $2: 1(\mathrm{~mol} / \mathrm{mol})$ in anhydrous dimethylformamide, and the $\mathrm{pH}$ of the reaction solution was adjusted to 9.0 using N-methyl morphine. The solution was then continuously stirred at room temperature for $24 \mathrm{~h}$. The reaction mixture was subsequently transferred into dialysis tubing (cut-off MW, $3000 \mathrm{Da}$ ) and dialyzed against deionized water for $48 \mathrm{~h}$. The resultant was then lyophilized and stored at $-20^{\circ} \mathrm{C}$. The product was confirmed using a MALDI-TOF-MS (Bruker Daltonics, Germany).

\section{Preparation and characterization of liposomes}

Liposomes were prepared using the film dispersion method, and drugs were loaded using the ammonium sulfate gradient loading method as previously 
reported [41]. Briefly, egg phosphatidylcholine, cholesterol, DSPE-PEG ${ }_{2000}$, DSPE-PEG ${ }_{2000}-\mathrm{c}(\mathrm{RGDyK})$ conjugate and dasatinib were dissolved in chloroform and methanol $(3: 1, \mathrm{v} / \mathrm{v})$ at a ratio of $66: 26: 2.5: 3: 3.5(\mathrm{~mol} / \mathrm{mol})$ in a pear-shaped bottle. The solvent was removed by a rotary vacuum evaporator, and the lipid film was hydrated with $250 \mathrm{mM}$ ammonium sulfate by water-bath sonication for $5 \mathrm{~min}$. The suspensions were subsequently treated using an ultrasonic cell disruptor for $10 \mathrm{~min}$ and successively extruded through polycarbonate membranes with pore sizes of 400 and $200 \mathrm{~nm}, 3$ times each. The suspensions obtained were dialyzed (cut-off MW, 12,000-14,000 Da) in Hepes buffered saline ( $25 \mathrm{mM}$ Hepes $/ 150 \mathrm{mM} \mathrm{NaCl}$ ) for $24 \mathrm{~h}$ and incubated with vincristine solution in a water bath at $40^{\circ} \mathrm{C}$ with continual shaking for $30 \mathrm{~min}$ (lipids: drug $=20: 1, \mathrm{w} / \mathrm{w}$ ). Then, functional vincristine plus dasatinib liposomes were obtained. Blank functional liposomes, vincristine plus dasatinib liposomes and vincristine liposomes were prepared using the same procedures by excluding the addition of dasatinib or DSPE-PEG ${ }_{2000^{-}}-\mathrm{R}$ (RDyK) conjugate or DSPE-PEG ${ }_{2000^{-}}$ $\mathrm{c}(\mathrm{RGDyK})$ conjugate and dasatinib, respectively, during the film formation process. Moreover, using fluorescent probes to evaluate the distribution in vivo, four types of liposomes were similarly prepared, including coumarin liposomes, functional coumarin liposomes (lipids: coumarin $=500: 1, \mathrm{w} / \mathrm{w})$, DiR liposomes and functional DiR liposomes (lipids: $\mathrm{DiR}=200: 1, \mathrm{w} / \mathrm{w}$ ).

The particle sizes, PDI and zeta potential values were measured using a Nano Series Zen 4003 Zetasizer (Malvern Instruments Ltd, Malvern, UK). The morphology of the liposomes was observed using an AFM (SPI3800N series SPA-400, Tokyo, Japan). The in vitro release of vincristine or dasatinib from the liposomes was achieved by dialysis against phosphate buffered saline (PBS, $\mathrm{pH} 7.4$ ) that contained $10 \% \mathrm{FBS}$ at $37^{\circ} \mathrm{C}$.

\section{Cellular uptake by TNBC cells and targeting effect}

Coumarin was used as a fluorescent probe to determine the cellular uptake. To evaluate the cellular uptake, MDA-MB-231 cells were seeded at a density of $4 \times 10^{5}$ cells/well in 6-well culture plates. After $24 \mathrm{~h}$, the cells were treated with free coumarin, coumarin liposomes and functional coumarin liposomes at a final concentration of $0.5 \mu \mathrm{M}$ coumarin for another $4 \mathrm{~h}$. Culture medium was used as a blank control. After incubation, the cells were collected to measure the fluorescence intensity using a flow cytometer (Becton Dickinson, USA) according to the manufacturer's instructions. Each assay was repeated in triplicate.

To evaluate the targeting effect, MDA-MB-231 cells were seeded into chambered cover slides at a density of $2 \times 10^{5}$ cells/dish. After $24 \mathrm{~h}$ incubation, the cells were treated with free coumarin, coumarin liposomes and functional coumarin liposomes at a final concentration of
$1 \mu \mathrm{M}$ coumarin for another $2 \mathrm{~h}$. Culture medium was used as a blank control. After incubation, the cells were fixed with $4 \%$ paraformaldehyde for $10 \mathrm{~min}$, and then blocked with $10 \%$ goat serum that contained $0.3 \mathrm{M}$ glycine for $2 \mathrm{~h}$ at room temperature. After being washed by PBS ( $\mathrm{pH} 7.4$ ), MDA-MB-231 cells were incubated with anti-integrin $\beta 3$ antibody (1:100 dilution, Abcam) at $4{ }^{\circ} \mathrm{C}$ overnight, followed by incubation with Alexa Fluor 647-conjugated (1:500 dilution, Abcam) at room temperature for $2 \mathrm{~h}$. After being washed by PBS, nuclei were stained with Hoechst $33342(2 \mu \mathrm{g} / \mathrm{mL})$ for $10 \mathrm{~min}$. Finally, the cells were imaged and analyzed using a confocal laser scanning fluorescent microscopy (Leica, Heidelberg, Germany).

\section{Inhibitory effects and induction of apoptosis on TNBC cells}

To compare the inhibitory effects of the different formulations, MDA-MB-231 cells were seeded at a density of 7000 cells/well in 96-well culture plates and cultured for $24 \mathrm{~h}$. The cells were subsequently treated with serial concentrations of the drug formulations. The final concentration of vincristine ranged between $0-1 \mu \mathrm{M}$, whereas the concentration of dasatinib was in the range of $0.1-1.0 \mu \mathrm{M}$. Culture medium was used as a blank control. After treatment for $48 \mathrm{~h}$, the inhibitory effects were determined using a sulforhodamine-B staining assay [42]. Survival rates were calculated using the following formula: survival $(\%)=\left(\mathrm{A}_{540 \mathrm{~mm}}\right.$ for treated cells $/ \mathrm{A}_{540 \mathrm{~mm}}$ for control cells) $\times 100 \%$, where $\mathrm{A}_{540 \mathrm{~nm}}$ is the absorbance at $540 \mathrm{~nm}$ as measured by a microplate reader (Infinite F50, Tecan Group Ltd., Shanghai, China).

Apoptosis was identified using a fluorescein annexin V staining kit (Biosea Biotechnology Co., Ltd, Beijing, China). MDA-MB-231 cells were seeded at a density of $4 \times 10^{5}$ cells/well in 6-well culture plates for $24 \mathrm{~h}$ at $37^{\circ} \mathrm{C}$. After $24 \mathrm{~h}$ incubation, the cells were treated with varying drug formulations at a concentration of 0.1 $\mu \mathrm{M}$ vincristine or dasatinib. Culture medium was used as a blank control. After incubation for $6 \mathrm{~h}$, the cells were handled according to the manufacturer's protocol and assessed via flow cytometry. Each assay was repeated in triplicate.

\section{Apoptotic signaling pathways of TNBC cells}

MDA-MB-231 cells were seeded in 96-well plates and incubated for $24 \mathrm{~h}$, followed by treatment with varying drug formulations at a concentration of $0.1 \mu \mathrm{M}$ vincristine or dasatinib. Culture medium was added as a blank control. After incubation for $6 \mathrm{~h}$, the cells were fixed with $4 \%$ formaldehyde for $15 \mathrm{~min}$, permeabilized with $0.5 \%$ Triton X-100 for 15 min and blocked with $10 \%$ goat serum that contained $0.3 \mathrm{M}$ glycine for $2 \mathrm{~h}$ at room temperature. The cells were subsequently incubated with the primary antibody (Sangon, China) at $4^{\circ} \mathrm{C}$ overnight, followed by incubation with the secondary antibody conjugated with 
Alexafluor-488 (OriGene, China) at room temperature for $2 \mathrm{~h}$. Both primary and secondary antibodies were properly diluted according to the instructions. Nuclei were stained with Hoechst $33342(2 \mu \mathrm{g} / \mathrm{mL})$ for $10 \mathrm{~min}$ at room temperature. The fluorescence intensity of each well was measured using the Operetta high content screening system and calculated with the Columbus system.

To evaluate the ROS-related apoptotic pathway, MDA-MB-231 cells were seeded in 6-well plates at a density of $3 \times 10^{5}$ cells/well and incubated for $24 \mathrm{~h}$. The formulation administrations were the same as previously described. After $6 \mathrm{~h}$ incubation with varying formulations, the cells were stained with $1 \mu \mathrm{M}$ DCFH-DA (Biotime, China) for $10 \mathrm{~min}$. The cells were then washed, harvested and re-suspended in PBS and determined immediately via flow cytometry.

\section{Destruction of VM channels of TNBC cells}

A matrigel-based tube formation assay was used to assess the destructive effect on the VM channels of MDA-MB-231 cells [43]. Briefly, culture plates (96-well) were coated with matrigel $(50 \mu \mathrm{L} /$ well $)$ and allowed to polymerize at $37^{\circ} \mathrm{C}$ for $30 \mathrm{~min}$. MDA-MB-231 cells were collected and resuspended with serum-free culture medium at a density of $1 \times 10^{4}$ cells/well and subsequently seeded in wells that contained varying formulations at a concentration of $0.01 \mu \mathrm{M}$ vincristine or dasatinib. Blank medium was used as a control. After incubation for $10 \mathrm{~h}$, each well was photographed and analyzed using an EVOS microscope.

The expression levels of six proteins (VE-Cad, FAK, PI3K, EphA2, MMP-2, and MMP-9) in MDA-MB-231 cells were determined using enzymelinked immunosorbent assay kits (Cusabio Biotech Co. Ltd., Beijing, China). Briefly, cells were cultured to $80 \%$ confluence and then treated with varying formulations for $12 \mathrm{~h}$. The final concentration of vincristine or dasatinib was $0.1 \mu \mathrm{M}$. Culture medium was used as a blank control. After incubation, the cells were harvested and lysed. The cell lysates were analyzed using a microplate reader according to the manufacturer's instructions for the kits.

\section{Destruction of TNBC tumor spheroids}

Multicellular tumor spheroids of MDA-MB-231 cells were grown in vitro using the liquid overlay system [44]. Briefly, agarose was added to serum-free culture medium and heated to $80^{\circ} \mathrm{C}$ for $30 \mathrm{~min}$ to form a $2 \%(w / v)$ solution. Each well of a $96-$ well culture plate was coated with $50 \mu \mathrm{L}$ agarose solution. After cooling to ambient temperature, MDA-MB-231 cells were seeded at a density of $1 \times 10^{3}$ cells/well with $100 \mu \mathrm{L}$ growth medium. The culture plates were gently shaken for $5 \mathrm{~min}$ and incubated for $48 \mathrm{~h}$ to form tumor spheroids.
To monitor the penetration ability, coumarin was used as a fluorescent probe. The MDA-MB-231 tumor spheroids were treated with free coumarin, coumarin liposomes, and functional coumarin liposomes for $12 \mathrm{~h}$, respectively. The final concentration of coumarin was 10.0 $\mu \mathrm{M}$. After incubation, the spheroids were washed with PBS and subsequently scanned at different layers from the top of the spheroids to the inside using the confocal laser scanning fluorescent microscope.

To evaluate the destructive effects of different formulations, MDA-MB-231 tumor spheroids were collected in 6-well culture plates and then treated with varying formulations at a concentration of $1 \mu \mathrm{M}$ vincristine or dasatinib. Culture medium was used as a blank control. After incubation for $48 \mathrm{~h}$, the spheroids were fixed by $2.5 \%$ glutaraldehyde for $60 \mathrm{~min}$, rinsed three times with PBS, dehydrated and embedded. The spheroids were subsequently observed under a scanning electron microscope (SEM, JSM-5600 LV, JEOL, Japan).

After a tumor spheroid was formed in a well, varying formulations were added at a concentration of 1 $\mu \mathrm{M}$ vincristine or dasatinib. Culture medium was used as a blank control. The inhibitory effect was evaluated via the measurement of the tumor spheroid under an inverted microscope. Briefly, the major $\left(\mathrm{d}_{\max }\right)$ and minor $\left(\mathrm{d}_{\min }\right)$ diameters of each spheroid were measured, and the spheroid volume was calculated as previously described by the following formula: $\mathrm{V}=\left(\pi \times \mathrm{d}_{\max } \times \mathrm{d}_{\min }\right) / 6$ [45]. The tumor spheroid volume ratio was subsequently calculated using the formula $\mathrm{R}=\left(\mathrm{V}_{\text {day }} / \mathrm{V}_{\text {day } 0}\right) \times 100 \%$, where $\mathrm{V}_{\text {day }}$ is the tumor spheroid volume at the ith day (day after drug treatments), and $\mathrm{V}_{\text {day } 0}$ is the tumor spheroid volume prior to treatment.

\section{Anticancer efficacy}

Approximately $1 \times 10^{7}$ MDA-MB-231 cells were subcutaneously injected into the right armpits of BALB/c female nude mice. Following growth to a volume of approximately $1000 \mathrm{~mm}^{3}$, the tumors were extracted, cut into pieces of approximately $2 \times 2 \times 2 \mathrm{~mm}^{3}$, and then seeded into the right armpits of fresh nude mice with a tumor inoculation needle. When the tumors reached approximately $100 \mathrm{~mm}^{3}$ in volume, the mice were randomly divided into five treatment groups $(n=6)$ and treated with physiological saline, free vincristine, vincristine liposomes, vincristine plus dasatinib liposomes, or functional vincristine plus dasatinib liposomes via the tail vein at days $12,14,16,18$, 20 and 22 after inoculation. The dosage of vincristine was $1 \mathrm{mg} / \mathrm{kg}$ (vincristine: dasatinib $=1: 1, \mathrm{~mol} / \mathrm{mol}$ ). The mice were weighed, and the tumors were measured with calipers. The tumor volumes $(\mathrm{V})$ were calculated with the formula $\mathrm{V}=\left(\right.$ length $\times$ width $\left.^{2}\right) / 2\left(\mathrm{~mm}^{3}\right)$, and the tumor volume ratios were evaluated with the formula $\mathrm{R}(\%)=\mathrm{V}_{\text {day }} / \mathrm{V}_{\text {day }}$ ${ }_{11} \times 100 \%$, where $\mathrm{V}_{\text {day } i}$ is the tumor volume at day $\mathrm{i}$, and $\mathrm{V}_{\text {day }}$ ${ }_{11}$ is the tumor volume at day 11 . 
A routine blood analysis of the mice was conducted using an MEK-6318K Hematology Analyzer (Nihon Kohden, Japan) prior to euthanasia. The mice were subsequently euthanized at day 25 via cervical dislocation. The tumor masses were carefully isolated to prepare cryosections for the TUNEL assay using an in situ apoptosis detection kit (KeyGen Biotechnology Co., Ltd, Nanjing, China). The FITClabeled TUNEL-positive cells were imaged via the confocal laser scanning fluorescent microscopy. To evaluate the in vivo destructive effect on VM channels, CD34 endothelial marker PAS dual staining was used [46]. Briefly, the assay was performed on the tumor slices using a CD34 antibody (1:300 dilution, Santa Cruz Biotechnology, USA), Peroxidase Kit (Santa Cruz Biotechnology, USA) and PAS staining according to the manufacturer's protocol and ultimately photographed using an EVOS microscope. Other organs were removed to create paraffin sections for hematoxylin and eosin staining for safety examination.

\section{In vivo imaging in mice}

Non-invasive optical imaging systems were used to observe the real-time distribution and tumor accumulation ability of DiR-loaded liposomes in MDA-MB-231 xenografts. When the tumors reached approximately $500 \mathrm{~mm}^{3}$ in volume, the mice were randomly divided into four groups $(3$ mice per group). The mice were subsequently administered physiological saline, free DiR, DiR liposomes, or functional $\mathrm{DiR}$ liposomes via the tail vein. The mice were then anesthetized with isoflurane and scanned at 1, 3, 6, 9, 12, 24 and 48 h using a Kodak multimodal imaging system (Carestream Health, Inc., USA). To further observe the distribution status, the mice were immediately euthanized to collect the tumor masses and major organs. The fluorescence signal intensities in different tissues were measured.

\section{Statistical analysis}

Data are presented as the means \pm standard deviations (SDs). One-way analysis of variance was used to determine the significance among the groups, after which post-hoc tests using a Bonferroni correction were used for multiple comparisons between individual groups. A $p$ value $<0.05$ was considered significant.

\section{CONCLUSIONS}

In this study, a type of nanostructured functional vincristine plus dasatinib liposomes was developed via modification with the targeting molecule DSPE-PEG ${ }_{2000}$ $\mathrm{c}(\mathrm{RGDyK})$. The liposomes exhibited a significant efficacy in TNBC MDA-MB-231 cells in vitro and in TNBC-bearing nude mice. The action mechanism involved the following aspects: (i) the pegylated liposomes and the nanostructured particle size resulted in prolonged circulation in the blood and more drug accumulation in the tumor tissue; (ii) the targeting molecule promoted cellular drug uptake; (iii) the induction of apoptosis potentiated the overall anticancer efficacy via activation of capases $(8,9$, and 3$)$, increased expression of Bax, decreased expression of Mcl-1, and generation of ROS; and (iv) the destructive effect on the VM channels prevented the residual cancer cells from the relapse after treatment via inhibition of VM channel indicators, which consisted of VE-Cad, FAK, PI3K, MMP-2, and MMP-9. It is concluded that the functional vincristine plus dasatinib liposomes may provide a potential strategy for treatment of TNBC along with elimination of VM channels.

\section{ACKNOWLEDGMENTS AND FUNDING}

This study was supported by grants from the National Natural Science Foundation of China (No. 81373343) and the Beijing Natural Science Foundation (No. 7131009).

\section{CONFLICTS OF INTEREST}

The authors declare no conflict of interests.

\section{REFERENCES}

1. Jemal A, Bray F, Center MM, Ferlay J, Ward E, Forman D. Global cancer statistics. CA Cancer J Clin. 2011; 61:69-90.

2. Redig AJ, McAllister SS. Breast cancer as a systemic disease: a view of metastasis. J Intern Med. 2013; 274:113-126.

3. Nielsen TO, Hsu FD, Jensen K, Cheang M, Karaca G, $\mathrm{Hu}$ Z, Hernandez-Boussard T, Livasy C, Cowan D, Dressler L, Akslen LA, Ragaz J, Gown AM, et al. Immunohistochemical and clinical characterization of the basal-like subtype of invasive breast carcinoma. Clin Cancer Res. 2004; 10:5367-5374.

4. Ortiz-Ruiz MJ, Álvarez-Fernández S, Parrott T, Zaknoen S, Burrows FJ, Ocaña A, Pandiella A, Esparís-Ogando A. Therapeutic potential of ERK 5 targeting in triple negative breast cancer. Oncotarget. 2014; 5:11308-11318.

5. Amos KD, Adamo B, Anders CK. Triple-negative breast cancer: an update on neoadjuvant clinical trials. Int J Breast Cancer. 2012; 2012:385978.

6. Dietze EC, Sistrunk C, Miranda-Carboni G, O’Regan R, Seewaldt VL. Triple-negative breast cancer in AfricanAmerican women: disparities versus biology. Nat Rev Cancer. 2015; 15:248-254. 
7. Zhang D, Sun B, Zhao X, Ma Y, Ji R, Gu Q, Dong X, Li J, Liu F, Jia X, Leng X, Zhang C, Sun R, Chi J. Twist1 expression induced by sunitinib accelerates tumor cell vasculogenic mimicry by increasing the population of CD133+ cells in triple-negative breast cancer. Mol Cancer. 2014; 13:207.

8. Liu TJ, Sun BC, Zhao XL, Zhao XM, Sun T, Gu Q, Yao Z, Dong XY, Zhao N, Liu N. CD133+ cells with cancer stem cell characteristics associates with vasculogenic mimicry in triple-negative breast cancer. Oncogene. 2013; 32:544-553.

9. van der Hage JA, Putter H, Bonnema J, Bartelink H, Therasse P. Impact of locoregional treatment on the earlystage breast cancer patients: a retrospective analysis. Eur J Cancer. 2003; 39:2192-2199.

10. de Haes JC, Curran D, Aaronson NK, Fentiman IS. Quality of life in breast cancer patients aged over 70 years, participating in the EORTC 10850 randomised clinical trial. Eur J Cancer. 2003; 39:945-951.

11. Chen J, Li S, Shen Q. Folic acid and cell-penetrating peptide conjugated PLGA-PEG bifunctional nanoparticles for vincristine sulfate delivery. Eur J Pharm Sci. 2012; 47:430-443.

12. Lombardo LJ, Lee FY, Chen P, Norris D, Barrish JC, Behnia K, Castaneda S, Cornelius LA, Das J, Doweyko AM, Fairchild C, Hunt JT, Inigo I, et al. Discovery of N-(2-chloro6-methyl- phenyl)-2-(6-(4-(2-hydroxyethyl)- piperazin-1-yl)2-methylpyrimidin-4- ylamino)thiazole-5-carboxamide (BMS-354825), a dual Src/Abl kinase inhibitor with potent antitumor activity in preclinical assays. J Med Chem. 2004; 47:6658-6661.

13. Acosta JJ, Muñoz RM, González L, Subtil-Rodríguez A, Dominguez-Caceres MA, García-Martínez JM, Calcabrini A, Lazaro-Trueba I, Martín-Pérez J. Src mediates prolactin-dependent proliferation of T47D and MCF7 cells via the activation of focal adhesion kinase/Erk1/2 and phosphatidylinositol 3-kinase pathways. Mol Endocrinol. 2003; 17:2268-2282.

14. Veracini L, Grall D, Schaub S, Beghelli-de la Forest Divonne S, Etienne-Grimaldi MC, Milano G, Bozec A, Babin E, Sudaka A, Thariat J, Van Obberghen-Schilling E. Elevated Src family kinase activity stabilizes E-cadherinbased junctions and collective movement of head and neck squamous cell carcinomas. Oncotarget. 2015; 6:7570-7583.

15. Finn RS, Dering J, Ginther C, Wilson CA, Glaspy P, Tchekmedyian N, Slamon DJ. Dasatinib, an orally active small molecule inhibitor of both the src and abl kinases, selectively inhibits growth of basal-type/"triple-negative" breast cancer cell lines growing in vitro. Breast Cancer Res Treat. 2007; 105:319-326.

16. Nam S, Williams A, Vultur A, List A, Bhalla K, Smith D, Lee FY, Jove R. Dasatinib (BMS-354825) inhibits Stat5 signaling associated with apoptosis in chronic myelogenous leukemia cells. Mol Cancer Ther. 2007; 6:1400-1405.

17. Shor AC, Keschman EA, Lee FY, Muro-Cacho C, Letson GD, Trent JC, Pledger WJ, Jove R. Dasatinib inhibits migration and invasion in diverse human sarcoma cell lines and induces apoptosis in bone sarcoma cells dependent on SRC kinase for survival. Cancer Res. 2007; 67:2800-2808.

18. Wang Z, Yu Y, Dai W, Lu J, Cui J, Wu H, Yuan L, Zhang $\mathrm{H}$, Wang $\mathrm{X}$, Wang J, Zhang $\mathrm{X}$, Zhang Q. The use of a tumor metastasis targeting peptide to deliver doxorubicin-containing liposomes to highly metastatic cancer. Biomaterials. 2012; 33:8451-8460.

19. Qiao Y, Huang X, Nimmagadda S, Bai R, Staedtke V, Foss CA, Cheong I, Holdhoff M, Kato Y, Pomper MG, Riggins GJ, Kinzler KW, Diaz LA Jr, Vogelstein B, Zhou S. A robust approach to enhance tumor-selective accumulation of nanoparticles. Oncotarget. 2011; 2:59-68.

20. Zucker D, Barenholz Y. Optimization of vincristinetopotecan combination - paving the way for improved chemotherapy regimens by nanoliposomes. J Control Release. 2010; 146:326-333.

21. Chen X, Plasencia C, Hou Y, Neamati N. Synthesis and biological evaluation of dimeric RGD peptide-paclitaxel conjugate as a model for integrin-targeted drug delivery. J Med Chem. 2005; 48:1098-1106.

22. Nie Y, Schaffert D, Rödl W, Ogris M, Wagner E, Günther M. Dual-targeted polyplexes: one step towards a synthetic virus for cancer gene therapy. J Control Release. 2011; 152:127-134.

23. Cao Z, Bao M, Miele L, Sarkar FH, Wang Z, Zhou Q. Tumour vasculogenic mimicry is associated with poor prognosis of human cancer patients: a systemic review and meta-analysis. Eur J Cancer. 2013; 49:3914-3923.

24. Shirakawa K, Wakasugi H, Heike Y, Watanabe I, Yamada S, Saito K, Konishi F. Vasculogenic mimicry and pseudo-comedo formation in breast cancer. Int $\mathrm{J}$ Cancer. 2002; 99:821-828.

25. Sun B, Zhang S, Zhao X, Zhang W, Hao X. Vasculogenic mimicry is associated with poor survival in patients with mesothelial sarcomas and alveolar rhabdomyosarcomas. Int J Oncol. 2004; 25:1609-1114.

26. Torchilin V. Tumor delivery of macromolecular drugs based on the EPR effect. Adv Drug Deliv Rev. 2011; 63:131-135.

27. Troiano L, Ferraresi R, Lugli E, Nemes E, Roat E, Nasi M, Pinti M, Cossarizza A. Multiparametric analysis of cells with different mitochondrial membrane potential during apoptosis by polychromatic flow cytometry. Nat Protoc. 2007; 2:2719-2727.

28. Tamaki H, Harashima N, Hiraki M, Arichi N, Nishimura N, Shiina H, Naora K, Harada M. Bcl-2 family inhibition sensitizes human prostate cancer cells to docetaxel and promotes unexpected apoptosis under caspase-9 inhibition. Oncotarget. 2014; 5:11399-11412.

29. Bantel H, Engels IH, Voelter W, Schulze-Osthoff K, Wesselborg S. Mistletoe lectin activates caspase-8/FLICE independently of death receptor signaling and enhances 
anticancer drug-induced apoptosis. Cancer Res. 1999; 59:2083-2090

30. Blagosklonny MV. Prospective strategies to enforce selectively cell death in cancer cells. Oncogene. 2004; 23:2967-2975.

31. Kusumoto K, Ishikawa T. Didodecyldimethylammonium bromide (DDAB) induces caspase-mediated apoptosis in human leukemia HL-60 cells. J Control Release. 2010; 147:246-252.

32. Porter AG, Jänicke RU. Emerging roles of caspase-3 in apoptosis. Cell Death Differ. 1999; 6:99-104.

33. Maji S, Samal SK, Pattanaik L, Panda S, Quinn BA, Das SK, Sarkar D, Pellecchia M, Fisher PB, Dash R. Mcl-1 is an important therapeutic target for oral squamous cell carcinomas. Oncotarget. 2015; 6:16623-16637.

34. Han J, Goldstein LA, Hou W, Rabinowich H. Functional linkage between NOXA and Bim in mitochondrial apoptotic events. J Biol Chem. 2007; 282:16223-16231.

35. Kim H, Rafiuddin-Shah M, Tu HC, Jeffers JR, Zambetti GP, Hsieh JJ, Cheng EH. Hierarchical regulation of mitochondrion-dependent apoptosis by BCL-2 subfamilies. Nat Cell Biol. 2006; 8:1348-1358.

36. Zou P, Zhang J, Xia Y, Kanchana K, Guo G, Chen W, Huang Y, Wang Z, Yang S, Liang G. ROS generation mediates the anti-cancer effects of WZ35 via activating JNK and ER stress apoptotic pathways in gastric cancer. Oncotarget. 2015; 6:5860-5876.

37. Martindale JL, Holbrook NJ. Cellular response to oxidative stress: signaling for suicide and survival. J Cell Physiol. 2002; 192:1-15.

38. Kirschmann DA, Seftor EA, Hardy KM, Seftor RE, Hendrix MJ. Molecular pathways: vasculogenic mimicry in tumor cells: diagnostic and therapeutic implications. Clin Cancer Res. 2012; 18:2726-2732.

39. Davies CD, Müller H, Hagen I, Gårseth M, Hjelstuen MH. Comparison of extracellular matrix in human osteosarcomas and melanomas growing as xenografts, multicellular spheroids, and monolayer cultures. Anticancer Res. 1997; 17:4317-4326.

40. Maruyama K, Yuda T, Okamoto A, Kojima S, Suginaka A, Iwatsuru M. Prolonged circulation time in vivo of large unilamellar liposomes composed of distearoyl phosphatidylcholine and cholesterol containing amphipathic poly(ethylene glycol). Biochim Biophys Acta. 1992; 1128:44-49.

41. Li X, Ruan GR, Lu WL, Hong HY, Liang GW, Zhang YT, Liu Y, Long C, Ma X, Yuan L, Wang JC, Zhang X, Zhang Q. A novel stealth liposomal topotecan with amlodipine: apoptotic effect is associated with deletion of intracellular $\mathrm{Ca} 2+$ by amlodipine thus leading to an enhanced antitumor activity in leukemia. J Control Release. 2006; 112:186-198.

42. Vichai V, Kirtikara K. Sulforhodamine B colorimetric assay for cytotoxicity screening. Nat Protoc. 2006; 1:1112-1116.

43. Liu T, Sun B, Zhao X, Gu Q, Dong X, Yao Z, Zhao N, Chi J, Liu N, Sun R, Ma Y. HER2/neu expression correlates with vasculogenic mimicry in invasive breast carcinoma. J Cell Mol Med. 2013; 17:116-122.

44. Kostarelos K, Emfietzoglou D, Papakostas A, Yang WH, Ballangrud A, Sgouros G. Binding and interstitial penetration of liposomes within avascular tumor spheroids. Int J Cancer. 2004; 112:713-721.

45. Dhanikula RS, Argaw A, Bouchard JF, Hildgen P. Methotrexate loaded polyether-copolyester dendrimers for the treatment of gliomas: enhanced efficacy and intratumoral transport capability. Mol Pharm. 2008; 5:105-116.

46. El Hallani S, Boisselier B, Peglion F, Rousseau A, Colin C, Idbaih A, Marie Y, Mokhtari K, Thomas JL, Eichmann A, Delattre JY, Maniotis AJ, Sanson M. A new alternative mechanism in glioblastoma vascularization: tubular vasculogenic mimicry. Brain. 2010; 133:973-982. 